\title{
Epistemics and attitudes*
}

\author{
Pranav Anand \\ University of California, Santa Cruz \\ Valentine Hacquard \\ University of Maryland
}

Submitted 2012-03-23 / Accepted 2012-05-24 / Revision received 2012-09-19 /

Published 2013-10-01

\begin{abstract}
This paper investigates the distribution of epistemic modals in attitude contexts in three Romance languages, as well as their potential interaction with mood selection. We show that epistemics can appear in complements of attitudes of acceptance (Stalnaker 1984), but not desideratives or directives; in addition, emotive doxastics (hope, fear) and dubitatives (doubt) permit epistemic possibility modals, but not their necessity counterparts. We argue that the embedding differences across attitudes indicate that epistemics are sensitive to the type of attitude an attitude predicate reports. We show that this sensitivity can be derived by adopting two types of proposals from the literature on epistemic modality and on attitude verbs: First, we assume that epistemics do not target knowledge uniformly, but rather quantify over an information state determined by the content of the embedding attitude (Hacquard 2006, 2010, Yalcin 2007). In turn, we adopt a fundamental split in the semantics of attitude verbs between 'representational' and 'non-representational' attitudes (Bolinger 1968): representational attitudes quantify over an information state (e.g., a set of beliefs for believe), which, we argue, epistemic modals can be anaphoric to. Non-representational attitudes do not quantify over an information state; instead, they combine with their complement via a comparison with contextually-provided alternatives using a logic of preference (cf. Bolinger 1968, Stalnaker 1984, Farkas 1985, Heim 1992,
\end{abstract}

* Many thanks to our very patient informants, especially Adrian Brasovaneau, Ivano Caponigro, Sofiana Chiriacescu, Anamaria Falaus, Ilaria Frana, Paula Menendez-Benito, Andres Salanova, and Luis Vicente. For additional helpful discussion, thanks to Cleo Condoravdi, Sam Cumming, Donka Farkas, Kai von Fintel, Anastasia Giannakidou, Jane Grimshaw, Patrick Grosz, Angelika Kratzer, Sven Lauer, Lisa Matthewson, Keir Moulton, Paul Pietroski, Paul Portner, Jessica Rett, Aynat Rubinstein, Hotze Rullmann, Philippe Schlenker, Dominique Sportiche, Hilda Koopman, Alexander Williams, Seth Yalcin, and audiences at DGfS 33, SALT 18, SPE 1, MIT, UCLA, UCSC, UMD, UChicago, UPenn, the ENS Sigma group, NYU and UBC. We are very grateful to Rick Nouwen and three anonymous S\&P reviewers for their insightful and detailed comments and suggestions.

(c)2013 Pranav Anand and Valentine Hacquard

This is an open-access article distributed under the terms of a Creative Commons NonCommercial License (creativecommons.org/licenses/by-nc/3.o). 
Villalta 2000, 2008). Finally, we argue that emotive doxastics and dubitatives have a hybrid semantics, which combines a representational component (responsible for licensing epistemic possibility modals), and a preference component (responsible for disallowing epistemic necessity modals).

Keywords: epistemics, modals, attitudes

\section{The distribution of epistemic modals in attitude contexts}

The nature of attitudinal predicates and the extent to which they are linguistically of a type has had a vexed history. The tradition owing to the work of Hintikka (1962) considers all attitude verbs universal quantifiers over possible worlds, in explicit analogy to the Kripke frame semantics for modal logic. The sole difference between various verbs is, as with Kripke frames, the accessibility relation, which determines the domain of the universal quantifier. This approach has an appealing simplicity, allowing a unified treatment of issues such as de dicto/de re ambiguities or substitutability, while still allowing for expression of the differences between desire and belief. Nonetheless, this view does not predict any major linguistic differences between classes of attitude predicates, since all attitudes alike quantify over possible worlds. However, attitude verbs do show important differences - e.g., the complementation behavior of attitude predicates is quite diverse, be it in terms of mood choice (e.g., Farkas 1992), variety of complementation (Stowell 1981, Pesetsky 1992, Kratzer 2006), question embedding (Karttunen 1977) or nominal complements (Moltmann 2003, Moulton 2008) - and these empirical challenges have led to various modifications of the Hintikkan uniformism.

This paper is part of the above reformative tradition, but we focus on a less well-studied distributional puzzle - the licensing behavior of epistemic modals, or, modals that express possibilities and necessities given a body of evidence. Consider the following examples:

(1) a. John thinks that Paul has to be innocent.

b. John said that Mary had to be the murderer.

c. John discovered that Mary had to be the murderer. 
Epistemics and attitudes

As shown in (1), the semi-modal have to ${ }^{1}$ with an epistemic interpretation can appear in the complements of doxastics and related attitudes. However, we claim that it is forbidden in the scope of desideratives and directives (this will be justified in section 2):

(2) a. John wishes that Paul had to be innocent.

*epistemic

b. John wants Paul to have to be the murderer.

c. John demanded that Paul have to be the murderer.

Note that the problem is truly specific to epistemic interpretations: the same modal with non-epistemic interpretations is grammatical, as below, where it receives a teleological interpretation (i.e., express a necessity given the circumstances and goals of the subject):

(3) a. John wishes that Paul had to take semantics to be a Ling major.

b. John wants Paul to have to take semantics to be a Ling major.

c. John demanded that Paul have to take semantics to be a Ling major.

In this paper, we aim at explaining what it is about epistemics ( $v s$. other modals), and what it is about attitudes that express desires and commands ( $v s$. doxastics) that can explain the patterns above. The division between doxastics and desideratives/directives is hardly new; they sit on opposite sides of several boundaries, perhaps the most famous being the indicativesubjunctive split. Across Romance languages, directives and desideratives take subjunctive complements, and, as we shall show, they likewise do not allow embedded epistemics.

A major assumption of this paper is that the negative correlation between epistemic modal licensing and the appearance of the subjunctive is not accidental. In particular, we will argue that epistemics may only appear in what Bolinger (1968) termed representational attitudes, those which 'convey a mental picture', that is, those that describe the content of a propositionally consistent attitudinal state.

\section{(4) Epistemic Licensing Generalization}

Epistemic modals are licensed only in representational attitudes

Bolinger's distinction was originally advanced to capture mood selection, but it has run afoul of notable peculiarities of subjunctive licensing in Ro-

1 We illustrate this in English with the semi-modal have to, since modal auxiliaries like must can't appear in the complements of directives and desideratives for syntactic reasons, regardless of their interpretation. 
mance: first, Italian pensare ('think') exceptionally governs the subjunctive (Farkas 1992). Second, emotives do not behave uniformly with respect to mood cross-Romance. Emotive factives (e.g., be happy) govern the indicative in Romanian, but the subjunctive in the rest of Romance. Emotive doxastics (hope, fear) tend to select for subjunctive, but French and Romanian hope also allow the indicative, and Romanian fear forces it (cf. Farkas 1992).

We argue that while Bolinger's characterization of mood selection in terms of representationality may be incorrect, it does accurately characterize the distribution of epistemic modals. Informally speaking, this is perhaps not unexpected - consistency and epistemic modality are intuitively related. But it is not obvious how to theoretically cash out this connection in terms of conventional views of attitudes and epistemic modality.

To see this, consider what standard accounts of attitudes and modality predict. As mentioned earlier, Hintikkan accounts treat attitude verbs as universal quantifiers over possible worlds, restricted by a lexically-determined accessibility relation (e.g., a doxastic relation picks out belief worlds for believe, a bouletic one, desire worlds for want):

(5) $\llbracket$ believe $\rrbracket^{w}=\lambda p_{s t} \cdot \lambda x . \forall w^{\prime} \in A c c_{\text {doxastic }}(w, x):\left[p\left(w^{\prime}\right)=1\right]$

(6) $\llbracket$ want $\rrbracket^{w}=\lambda p_{s t} \cdot \lambda x \cdot \forall w^{\prime} \in A c c_{\text {bouletic }}(w, x):\left[p\left(w^{\prime}\right)=1\right]$

Modals are likewise quantifiers over possible worlds in the Kripkean tradition, with modal flavor determined by different accessibility relations. Whereas attitude verbs lexically encode their accessibility relations, those of modals are contextually-determined via conversational backgrounds (Kratzer 1977, 1981, 1991): an epistemic conversational background ( $\left.f_{\text {epistemic }}\right)$ determines a set of relevant known facts, a deontic one ( $\left.f_{\text {deontic }}\right)$, a set of relevant laws, etc.

(7) $\llbracket$ must $\rrbracket^{w, f}=\lambda p_{s t} . \forall w^{\prime} \in \cap f(w):\left[p\left(w^{\prime}\right)=1\right]$

(8) $\llbracket \operatorname{can} \rrbracket^{w, f}=\lambda p_{s t} . \exists w^{\prime} \in \cap f(w):\left[p\left(w^{\prime}\right)=1\right]$

(9) a. $\cap f_{\text {epistemic }}(w)=\lambda w^{\prime} \cdot w^{\prime}$ is compatible with what is known in $w$

b. $\cap f_{\text {epistemic }}(w)=\lambda w^{\prime} \cdot w^{\prime}$ is compatible with the laws in $w$

When an epistemic modal appears in the complement of an attitude verb like believe, as in (10a), we obtain the roughly correct truth conditions in (1ob): 
Epistemics and attitudes

(10) a. John believes that Mary has to be the murderer.

b. In all worlds $w^{\prime}$ compatible with J.'s beliefs in $w$, all worlds $w^{\prime \prime}$ compatible with what is known in $w^{\prime}$ are such that M. is the murderer in $w^{\prime \prime}$

Given that want differs form believe only in the domain quantified over, (11a) should yield the truth conditions in (11b). Instead, it is unacceptable when have to is interpreted epistemically.

(11) a. John wants Mary to have to be the murderer.

b. In all worlds $w^{\prime}$ compatible with J.'s desires in $w$, all worlds $w^{\prime \prime}$ compatible with what is known in $w^{\prime}$ are s. t. M. is the murderer in $w^{\prime \prime}$

The embedding differences across attitudes indicate that epistemics are sensitive to the type of attitude an attitude predicate reports, a fact that traditional analyses cannot explain. We will show that this sensitivity can be derived by adopting two proposals, one about epistemics, one about attitude verbs. First, we will assume that epistemics do not target knowledge uniformly, but rather quantify over an information state determined by the embedding attitude (Hacquard 2006, 2010, Yalcin 2007). In turn, we will claim that only representational attitudes can provide such an information state, and hence license epistemics. Non-representational attitudes, on the other hand, have an entirely different semantics, based on a logic of ordering of preferences (cf. Bolinger 1968, Stalnaker 1984, Farkas 1985, Heim 1992, Villalta 2000, 2008). We will argue that because of this ordering semantics, non-representational attitudes do not provide an information state that can license epistemics.

Given such an account, non-representational attitudes have a preferencebased semantics. However, we can ask whether the converse is true: do all preference-based attitudes have to be non-representational? Could there be a third class of attitude verbs, with both a representational component and a preference component?

This may be the case for what we will call emotive doxastics (hope, fear) (Portner 1992, Truckenbrodt 2006, Scheffler 2008, Falaus 2010). Hope and fear clearly have a (dis)preference component. But they also seem to have a doxastic component, differentiating them from desideratives like want, and evidenced, for instance, by the dialogue below from Scheffler 2008, attributed 
to Hubert Truckenbrodt (the example is in German, but the same contrast holds between English and Romance hope and want):

A: Kommt Peter heute? (Scheffler 2008) comes Peter today 'Is Peter coming today?'

B: Ich hoffe/*will, dass er heute kommt. I hope/*want that he today comes. 'I hope/“want that he is coming today.'

B's answer with hope is felicitous, unlike with want. Scheffler argues that this felicity with hope is due to its doxastic component: B asserts with hope $p$ that $p$ is a possibility, hence providing a partial answer to A's question. If hope and fear have such a representational doxastic component, we expect they should license epistemics. On the other hand, we may ask if their preference component might interfere.

We finally consider a last category, dubitatives (doubt), which, like emotive doxastics, also seem to share properties with both representational and preference-based attitudes. Dubitatives clearly have a doxastic component, but, as we will see, they may also have an ordering component (not so much in terms of preferences per se, but in terms of likelihood). Like representational attitudes, doubt can be used felicitously in a dialogue like (12), but like preference-based attitudes, it selects for subjunctive in Romance.

In this paper, we examine the connection between mood, epistemicity, representationality and preferences, by investigating the distribution of epistemics for these four classes of attitudes: representational (doxastics, argumentatives, semifactives), non-representational (desideratives, directives) and hybrid attitudes: emotive doxastics and dubitatives. Based on a survey of French, Italian, and Spanish, we show in section 2 that while doxastics, argumentatives and semifactives allow epistemics in their complements, desideratives and directives forbid them. Emotive doxastics and dubitatives show an interaction involving modal quantificational force: only possibility epistemics are acceptable. Section 3 presents our proposal for epistemics and attitude verbs, and their compatibility. Section 4 focuses on emotive doxastics and dubitatives, and discusses the relationship between mood, epistemicity, representationality and preferences. Section 5 discusses alternative proposals and section 6 concludes. 
Epistemics and attitudes

\section{The data}

In this section, we take a closer look at the distribution of epistemics in complements of attitudes, with an eye to determining when they are acceptable and how this acceptability interacts with mood selection. To this end, surveys were conducted in three Romance languages (French, Italian, and Spanish); full details on the survey methodology and results are provided in the Appendix. These languages share a core group of predicates that require subjunctive mood (directives and desideratives), but there are cross-linguistic differences as well (e.g., think in Italian selects for subjunctive, some French speakers prefer the indicative with hope).

\subsection{Attitudes of acceptance vs. desideratives and directives}

Considering the contrast laid out in (1-2), Anand \& Hacquard (2009) propose that epistemics are only acceptable underneath attitudes of acceptance (Stalnaker 1984), or attitudes said to be correct when the proposition expressed by their complement is true (for instance, if 'John believes that $p$ ', John's belief is correct if $p$ is true). This means that we should find epistemics in complements of doxastic verbs, verbs of communication and argumentation, but not in complements of desideratives and directives, as indicated in (1) and (2), respectively. ${ }^{2}$

Systematic investigation of this claim is stymied by the syntax of English modals. As English modals are auxiliaries (Huddleston \& Pullum 2002), they may only occur in finite complements, a fact which prevents examination of modal embedding under many attitude verbs, especially those from the directive/desiderative classes. Examination of modals is comparatively simpler in Romance languages, where modals are full verbs and may thus appear in most non-finite environments. Furthermore, many directives and desideratives take subjunctive in Romance rather than infinitivals, so we can test the semantic distribution of epistemic modals more generally.

To test Anand \& Hacquard (2009)'s claim directly, a seven-point acceptability survey was conducted in three Romance languages (French, $n=31$; Italian, $\mathrm{n}=11$; and Spanish, $\mathrm{n}=21$ ), contrasting the behavior of epistemic uni-

2 Fiction predicates (oneirics such as dream and suppositionals such as imagine) also admit epistemics, though these are not attitudes of acceptance. Note, however, that they are representational, as pointed out by Farkas (1992). We will use the term 'attitude of acceptance' loosely, with the intention to also include fiction predicates. 
Pranav Anand and Valentine Hacquard

\begin{tabular}{llll}
\hline FAMILY & CLASS & MEAN (SD) & MEDIAN \\
Core Indicative & doxastics/argumentatives & $6.2(1.7)$ & 7 \\
& semi-factives & $5.8(1.7)$ & 7 \\
Core Subjunctive & desideratives/directives & $2.7(2)$ & 2
\end{tabular}

Table 1 Mean/Median acceptability ratings for the core indicatives and subjunctives

versal and possibility modals in the scope of four families of attitude verbs: the core indicative classes (doxastics, argumentatives, semi-factives), the core subjunctive classes (desideratives and directives), emotive doxastics and dubitatives. The survey results were analyzed according to a mixed effects ordinal logistic regression with subject as a random effect; determinations of significance come from this analysis, which is detailed in the Appendix. All three languages showed the same pattern. For the balance of this discussion, we will illustrate with French examples, though all data presented in the text is pooled across these three languages (cf. Appendix for cross-linguistic comparison).

We will begin by comparing the core indicatives and subjunctives. Figure 1 contrasts the raw acceptability ratings for these two families, which are given in Table 1. The contrast between these families is significant (see the Appendix for details).

Epistemics are acceptable in complements of doxastics (13), argumentatives (14), and semi-factives (15). ${ }^{3}$

(13) Jean pense que Marie doit avoir connu son tueur. Jean thinks that Marie must-IND have known her killer 'John thinks that Mary must have known her killer'

3 French pouvoir and devoir and their Italian and Spanish equivalents allow both root and epistemic interpretations. French and Italian pouvoir are said to prefer root interpretations, generally, while Spanish poder appears to be more neutral. To guard against root interpretations, we constructed sentences that strongly favor an epistemic interpretation, by either having stative complements or by having them in the perfect, as in (14), which disallows root interpretations. To test this possibility more directly, a follow-up survey was conducted on a subset of the French informants on the unambiguously epistemic French se pouvoir. We obtained the same acceptability pattern as reported here (cf. Appendix). 


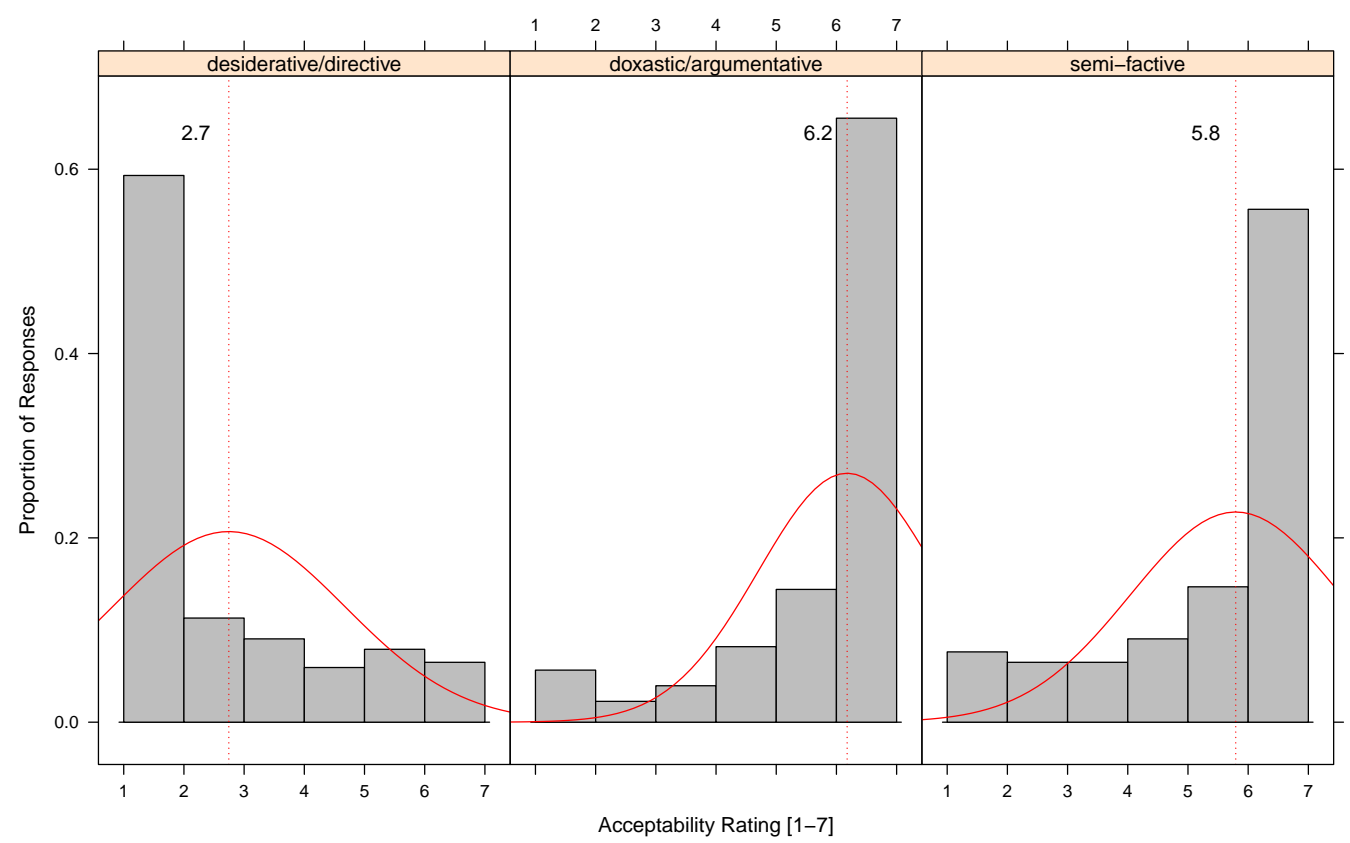

Figure 1 Acceptability ratings (from $1=$ unacceptable to $7=$ completely acceptable) for epistemics (might and must) under desideratives/directives, doxastics/argumentatives, and semi-factives. Gray bars indicate proportion of responses and solid lines kernel density estimation of the background distribution.

(14) Jean a \{dit; conclu\} que Marie devait avoir connu Jean has $\{$ said; concluded $\}$ that $M$. must-IND.IMPF have known son tueur.

her killer

'John \{said, concluded\} that Mary must have known her killer'

(15) Jean a réalisé que Marie devait avoir connu son tueur. Jean has realized that Marie must-IND.IMPF have known her killer 'John realized that Mary must have known her killer'

In contrast, and in line with the data from English in (2), epistemics are markedly degraded in complements of desideratives (16) and directives (17): 
Pranav Anand and Valentine Hacquard

(16) \#Jean veut que Marie doive avoir connu son tueur. Jean wants that Marie must-SUBJ have known her killer 'John wants that Mary must have known her killer'

(17) \#Jean a exigé que Marie doive avoir connu son tueur. Jean has demanded that Marie must-SUBJ have known her killer 'John demanded that Mary must have known her killer'

\subsection{Emotive doxastics and dubitatives}

Epistemic frequency under emotive doxastics is modulated by quantificational force: they allow epistemic possibility modals (like doxastics, argumentatives, and semifactives) but they disallow necessity modals.

(18) Jean craint que Marie puisse avoir connu son tueur. Jean fears that Marie can-SUBJ have known her killer

'John fears that Mary may have known her killer'

(19) \#Jean craint que Marie doive avoir connu son tueur. Jean fears that Marie must-SUBJ have known her killer

'John fears that Mary must have known her killer'

The same asymmetry is found with dubitatives:

(20) Jean doute que Marie puisse avoir connu son tueur. Jean doubts that Marie can-SUBJ have known her killer

'John doubts that Mary may have known her killer'

(21) \#Jean doute que Marie doive avoir connu son tueur. Jean doubts that Marie must-SUBJ have known her killer

'John doubts that Mary must have known her killer'

Figure 2 shows the acceptability judgments for these classes, broken down by modal, and Table 2 provides descriptive statistics. We will return to these in section 6. Readers are directed to the Appendix for summary statistics for might and must in desiderative/directive and acceptance attitudes. Under these attitudes, might and must are both unacceptable or acceptable, respectively, although note that must is more degraded that might in desiderative contexts. 


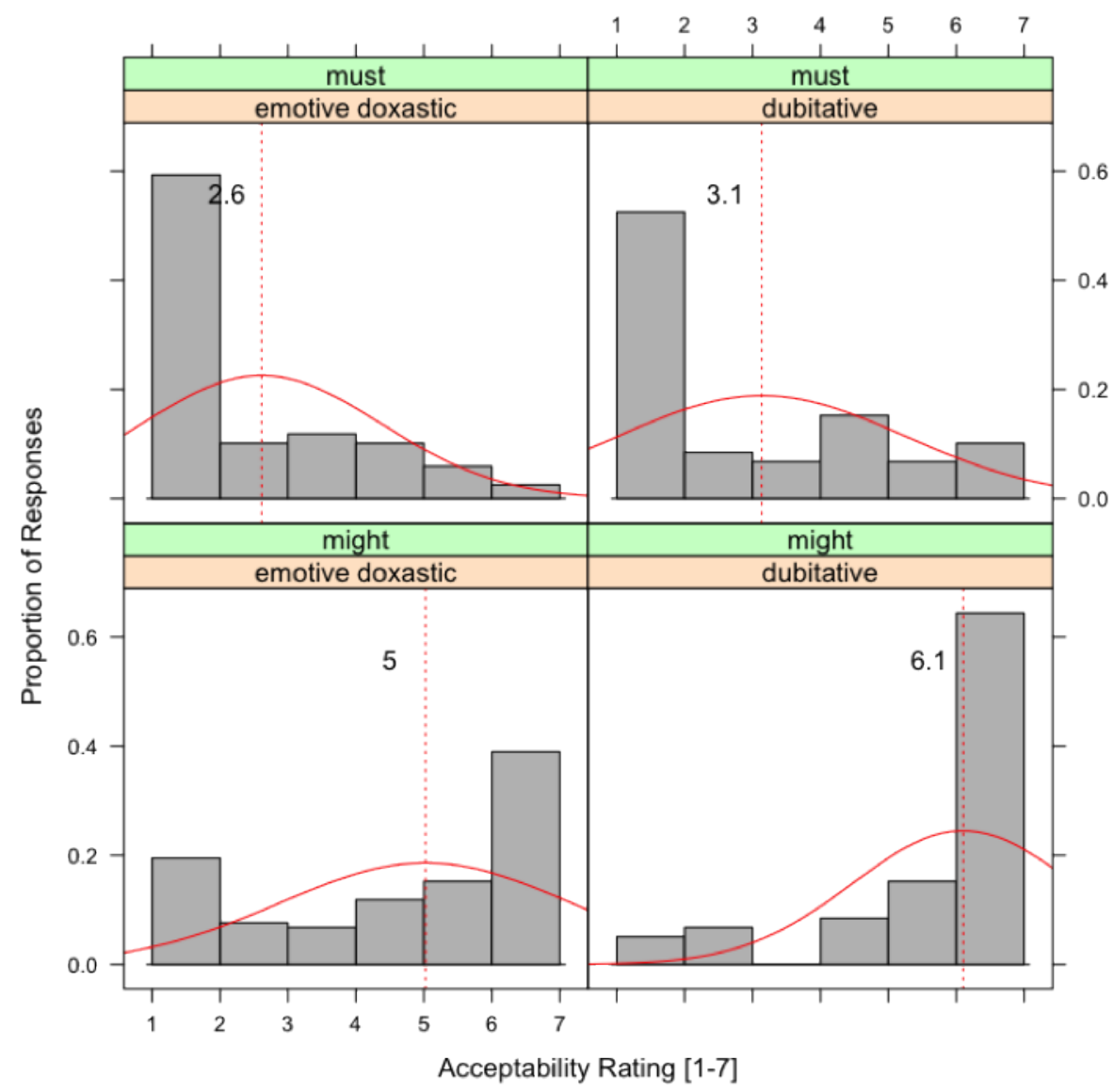

Figure 2 Acceptability ratings (from $1=$ unacceptable to $7=$ completely acceptable) for epistemics in complements of emotive doxastics and dubitatives.

To sum up, our cross-Romance survey show that epistemics consistently appear in the complements of certain classes of attitude verbs, and are disallowed in the complements of other classes. The results are summarized in Table 3 .

\subsection{Escape hatches}

Although we indicate that desideratives and directives are unacceptable with epistemics generally, and emotive doxastics and dubitatives with necessity epistemics, speakers occasionally find them acceptable. This occurs in sce- 
Pranav Anand and Valentine Hacquard

\begin{tabular}{lllll}
\hline & EMOTIVE DOXASTICS & & DubitATIVES \\
& Mean $(\mathrm{sd})$ & Median & Mean $(\mathrm{sd})$ & Median \\
must & $2.6(1.8)$ & 2 & $3.1(2.1)$ & 2 \\
might & $5.0(2.1)$ & 6 & $6.1(1.6)$ & 7
\end{tabular}

Table 2 Mean/Median acceptability ratings for emotive doxastics and dubitatives

\begin{tabular}{lll}
\hline ATTITUDE & might & must \\
Doxastics & $\checkmark$ & $\checkmark$ \\
Argumentatives & $\checkmark$ & $\checkmark$ \\
Semi-factives & $\checkmark$ & $\checkmark$ \\
Desideratives & X & X \\
Directives & X & X \\
Emotive Doxastics & $\checkmark$ & X \\
Dubitatives & $\checkmark$ & X
\end{tabular}

Table 3 Compact representation of acceptability judgments, by attitude and modal force

narios in which, informally, the attitude holder is considering the epistemic state of someone other than herself, such as when dealing with fictional worlds (e.g., reading a book or watching a TV show). (22) presents a reading of an epistemic under a desiderative which meets this requirement, in which John wants certain facts to obtain according to the author of the mystery novel.

(22) Jean veut que Marie doive avoir connu son tueur. Jean wants that Marie must-SUBJ have known her killer 'John wants that in the world of the mystery novel Mary must have known her killer'

We will call such cases in which the epistemic is targeting some unexpressed individual's epistemic state 'escape hatch readings', and return to them in section 3.4. 
Epistemics and attitudes

\section{Proposal}

The central goal of our proposal is to capture the distribution of epistemics in attitude environments based on the lexical semantics of the relevant attitudes. There are two empirical facts we need to account for:

i. Predicates of acceptance vs. desideratives/directives: Why are epistemics acceptable in the complement of the former but not the latter?

ii. Emotive doxastics and dubitatives: Why do they allow epistemic possibility but not necessity modals?

In a nutshell, we will propose an account of fact 1 which builds on two families of proposals: one about epistemics, the other about attitudes. The first will be the claim that the quantificational domains of epistemics are determined by anaphoric reference to an embedding attitude (Veltman 1996, Hacquard 2006, 2010, Yalcin 2007), and demand that the attitude in question has informational content. The second will be a claim about which attitudes have such content. We will propose that there are (at least) two classes of attitude verbs, giving rise to fundamentally different semantics: attitudes of acceptance are representational (Bolinger 1968): they pick out a consistent set of propositions that collectively define a non-trivial set of possible worlds, and are thus formalizable within a classic Hintikkan framework. Desideratives and directives, on the other hand, are not representational. As a result, an epistemic in their immediate scope will be unlicensed. We will assume that such attitudes have a comparative semantics, combining with their complement proposition not via their information content but by comparing it to contextual alternatives (Bolinger 1968, Stalnaker 1984, Heim 1992, Farkas 2003, Villalta 2000, 2008). Foreshadowing that proposal, we will call desideratives and directives preference-oriented attitudes. ${ }^{4}$

To account for fact 2, we will build on recent work which suggests that emotive doxastics have a hybrid semantics that involves both a representational component (which distinguishes them from pure desideratives like

4 While it is logically possible to give acceptance attitudes a preference-based semantics (e.g., in terms of probability) or desideratives a representational semantics (as in the Hintikkan tradition), we claim that treating the former as representational and the latter as preference-based provides a solution to our epistemics puzzle. While this proposal jives well with intuitions about belief and desire, this claim is strictly linguistic, and we remain agnostic about the attitudes themselves. We are committed to belief reports invoking a representational semantics, but allow that beliefs themselves be inconsistent. 
want), and a preference component (which distinguishes them from pure doxastics like think). Their representational component is what licenses epistemic possibility modals. Necessity epistemics are ruled out due to an incompatibility between the certainty of a necessity epistemic claim and the uncertainty associated with having several alternatives that preferences range over. We will extend this proposal to dubitatives.

This section is organized as follows: sections 3.1 and 3.2 discuss the semantics we assume for epistemic modality and attitudes; section 3.3 derives the distribution of epistemics in attitude contexts and section 3.4 discusses escape hatches. We turn to the semantics of emotive doxastics and dubitatives, and explain the modal force asymmetry puzzle in section 4 .

\subsection{Epistemic modality revisited}

The literature on epistemics has been concerned with two central issues: the semantic function of epistemics and the source of the epistemic authority. In the Kratzerian framework, modals are quantificational operators; modal flavor is determined by contextually-provided conversational backgrounds. However, unlike root modals, epistemics notoriously resist embedding (under tense, negation, quantifiers, in questions, antecedents of conditionals ...). This fact has lead many to postulate that epistemics do not contribute truth conditional content, but instead, express a 'comment', 'confidence', or 'probability assignment' from the speaker regarding the sentence (cf. Halliday 1970, Palmer 2001, Drubig 2001, Swanson 2006, a.o.). Given the data in section 2, we assume that the quantificational treatment of epistemics is correct: they contribute truth conditional content and may be embedded.

The other central issue in the epistemic literature is the nature of the modal base epistemics quantify over. Under one prominent line of analysis, epistemics uniformly quantify over a set of doxastic alternatives; the debate in this community is whether these alternatives are characterized by knowledge or belief and whether the belief is dependent on the speaker/attitude holder (Stephenson 2007) or the community (DeRose 1991, Egan, Hawthorne \& Weatherson 2004).

Another line of analysis has suggested that epistemics obtain their modal bases via anaphoric reference (Veltman 1996, Hacquard 2006, 2010, Yalcin 2007). One piece of evidence for this approach comes from a contrast noticed by Yalcin (2007) between belief predicates and epistemics when embedded under suppositional attitudes. As Yalcin observes, there is a felicity contrast 
Epistemics and attitudes

between the imperatives in (23a) and (23b), which differ in whether the second conjunct of the embedded clause contains a belief predicate or an epistemic modal.

(23) a. Imagine that [it's raining but you don't believe it is].

b. \#Imagine that [it's raining but it might not be].

Yalcin points out that if the modal base for an embedded epistemic is the same as the quantificational domain of the embedding attitude, then (23b) is contradictory, unlike (23a). To see this, assume that imagine is a universal quantifier over those worlds compatible with what the imaginer is actively imagining, $I M G_{x, w}$ :

(24) 【imagine $\rrbracket^{c, w, g}=\lambda p_{s t} . \lambda x . \forall w^{\prime} \in I M G_{x, w}:\left[p\left(w^{\prime}\right)=1\right]$

Given this and the identification of the modal base with $\mathrm{IMG}_{x, w}$, the sentences in (23) have the logical forms in (25):

(25) a. $\forall w^{\prime} \in I M G_{a d d(c), w}:\left[\operatorname{rain}\left(w^{\prime}\right) \wedge \forall w^{\prime \prime} \in D O X_{a d d(c), w^{\prime}}:\left[\neg \operatorname{rain}\left(w^{\prime \prime}\right)\right]\right]$. All worlds compatible with the addressee's imagination are ones in which it is raining and the addressee has a belief that it is not raining.

b. $\forall w^{\prime} \in I M G_{a d d(c), w}:\left[\operatorname{rain}\left(w^{\prime}\right) \wedge \exists w^{\prime \prime} \in I M G_{a d d(c), w}:\left[\neg \operatorname{rain}\left(w^{\prime \prime}\right)\right]\right]$ All worlds compatible with the addressee's imagination are ones in which it is raining and there is a world compatible with the addressee's imagination in which it is not raining.

While (25a) is non-contradictory (i.e., the addressee imagines herself as mistaken), in (25b) the use of the same set of worlds, $I M G_{a d d(c), w}$, for both the epistemic and the attitudinal operator results in vacuous quantification by the attitudinal operator over the second conjunct. This results in a contradiction: the first conjunct makes a universal claim about raining in $I M G_{a d d(c), w}$ worlds, while the second conjunct claims that there is a world in $I M G_{a d d(c), w}$ in which it is not raining.

The key to this solution is the mechanism by which epistemics retrieve a quantificational domain from the embedding attitude. Several alternatives exist in the literature: Veltman (1996) assumes that epistemics serve as dynamic tests on an information state or set of worlds under consideration, something that attitudes may effect. MacFarlane (2011) proposes that epistemics obtain their modal base from a context of assessment, which again may be manipulated by embedding attitudes. Hacquard $(2006,2010)$ argues that all modal bases are relativized to events, and that attitude predicates introduce event 
variables that epistemics pick up on. In this paper, for reasons of simplicity, we will follow Yalcin's own account.

Following Veltman (1996), Yalcin assumes that epistemics make claims with respect to an information state parameter of evaluation, $S: 5,6$

$$
\llbracket \text { might } \phi \rrbracket^{c, w, S, g}=1 \text { iff } \exists w^{\prime} \in S:\left[\llbracket \phi \rrbracket^{c, w^{\prime}, S, g}=1\right]
$$

When unembedded, the $S$ parameter is assumed to be contextuallyprovided (perhaps according with the range of potential epistemic authorities that have been argued for in the literature). Yalcin proposes that suppositional predicates update $S$ with the set of worlds they quantify over, as in (27) below:

(27) 【imagine $\phi \rrbracket^{c, w, S, g}=\lambda x \forall w^{\prime} \in S^{\prime}:\left[\llbracket \phi \rrbracket^{c, w^{\prime}, S^{\prime}, g}=1\right]$, where $S^{\prime}=I M G_{x, w}$

The fact that imagine passes along its quantificational domain in S results in the vacuous quantification observed above: might quantifies directly over the imagination state:

$$
\begin{aligned}
& \llbracket \text { imagine might } \phi \rrbracket^{c, w, S, g}=\lambda x \forall w^{\prime} \in S^{\prime}:\left[\llbracket \text { might } \phi \rrbracket^{c, w^{\prime}, S^{\prime}, g}=1\right] \\
& =\lambda x . \forall w^{\prime} \in S^{\prime}\left[\exists w^{\prime \prime} \in S^{\prime}:\left[\llbracket \phi \rrbracket^{c, w^{\prime \prime}, S^{\prime}, g}=1\right]\right] \\
& =\lambda x . \exists w^{\prime \prime} \in S^{\prime}:\left[\llbracket \phi \rrbracket^{c, w^{\prime \prime}, S^{\prime}, g}=1\right] \\
& \text { where } S^{\prime}=I M G_{x, w}
\end{aligned}
$$

Though (27) is stated in terms of imagine, we may generalize it for all attitudes as in (29) below.

(29) For any attitude $a t t$,

$\llbracket$ att $\phi \rrbracket^{c, w, S, g}=\lambda x \forall w^{\prime} \in S^{\prime} \llbracket \phi \rrbracket^{c, w^{\prime}, S^{\prime}, g}=1$, where $S^{\prime}$ is the quantificational domain provided by att.

This semantic generalization predicts that epistemics will be licensed under all attitudes, assuming all attitudes provide an information state. In the following section, we propose that providing an information state is simply the same as being representational, thus accounting for the failure of epistemics in the scope of non-representational attitudes.

5 The principle difference between Veltman and Yalcin's accounts is that the former is dynamic and the latter static.

6 Because these anaphoric proposals result in prolific vacuous quantification, we adopt the notational convention of using roman letters ( $p, q, r$, etc.) for unmodalized propositions and Greek letters ( $\phi, \psi$, etc.) for modalized and unmodalized propositions. 
Epistemics and attitudes

\subsection{Representational vs. non-representational attitudes}

While the semantics discussed in 3.1 was introduced to handle epistemics, note that (29) organizes the semantics of attitudinal complementation in general around information states, even when the complement contains no explicit modal (the attitude quantifies over the worlds of the information state). Representational attitudes, hence, combine with their complements via the associated information state. We hypothesize that non-representational attitudes do not supply an information state, and that this is why they fail to license epistemics. But if that's the case, we must derive the compositional behavior with their complements by other means.

The idea for a semantic split between two kinds of attitudes is fairly old. Formal epistemologists have long argued that non-representational attitudes invoke an ordering of preferences, in sharp contrast to the logic of belief governing representational attitudes (Hallden 1957, von Wright 1963). In the linguistic literature, many have argued that non-representational attitudes invoke ordering between alternatives (e.g., Bolinger 1968, Stalnaker 1984, Heim 1992, Farkas 2003). In section 3.2.1 we briefly review previous semantic proposals to account for these two different classes of verbs, and how mood selection (and other syntactic reflexes) relates to these classes. In section 3.2.2, we review Villalta's (2000, 2008) particular proposal for non-representational attitudes, which we adopt to account for their incompatibility with epistemics.

\subsubsection{Mood and attitudes}

Before we turn to proposals for mood selection, we should note that mood is just one of the syntactic reflexes that point to a fundamental difference in representationality amongst attitudes. Attitudes differ in whether they allow so-called parenthetical interpretations (Urmson 1952, Hooper 1975, Rooryck 2001, Simons 2007), whereby the complement clause can carry the main point of the assertion (Hooper \& Thompson 1973, Hooper 1975): representational (or 'assertive') predicates can, non-representational ones cannot. This ability seems to correlate with various syntactic reflexes crosslinguistically, all of which could be viewed as giving the embedded clause a sort of main clause syntax (Dayal \& Grimshaw 2009): indicative mood selection in Romance, preposing in English (30a), verb second complements in German ((30c) vs. (30b)) (cf. Bolinger 1968, Hooper \& Thompson 1973, Hooper 1975, Truckenbrodt 2006, Scheffler 2008): 
(30) a. John is home, Mary said/"wanted.

b. Ich denke/will, dass er heute kommt.

I think/want that he today comes

c. Ich denke/*will, dass er kommt heute.

I think/want, that he comes today

Hence, mood selection in Romance has cross-linguistic correlates which cut the attitude predicates pie into roughly the same two semantic classes: representational attitudes and preference-based, non-representational attitudes.

Although proposals for mood selection vary quite widely, there is a general consensus that mood selection reflects semantic differences (Bolinger 1968, Hooper 1975, Farkas 1985, Giannakidou 1997, Portner 1997, Giorgi \& Pianesi 1997, Quer 1998, a.o.). At a general level, indicative-selecting attitudes describe a judgment of truth (Bolinger's representational attitudes, Searle \& Vanderveken 1985's word-to-world fit attitudes), while those that take the subjunctive express preferences (non-representational or world-to-word fit attitudes).

How this general idea is to be cashed out is a matter of debate. For the indicative, most theories focus on commitment to truth of the embedded proposition, either by the attitude holder or the speaker. For Farkas (1985, 1992, 2003), attitudes that select for the indicative (i.e., her 'weak intensional' predicates) require that the attitude holder believes the proposition to be true, either in the actual world or in the attitude world (e.g., dream world, communication world ....). For Giannakidou $(1997,1999)$ indicative-selection correlates with veridicality: veridical predicates require that the embedded proposition be true according to the subject in all worlds of a relevant set of worlds (a 'model'), e.g., the subject's belief-model, dream-model, communication model), etc. For Portner (1997), the indicative is selected when attitudes are 'prototypically factive' (when 'x says/thinks that $p$ ', $p$ is prototypically true). For Schlenker (2005), the indicative marks some notion of commitment from either the speaker or the subject.

For subjunctive-selection, there is a greater range in analyses. Some (e.g., Schlenker 2005) analyze subjunctive-selecting attitudes as an elsewhere condition - they are simply those than lack a notion of commitment. Here, we will follow the line of proposals according to which such attitudes involve an ordering of preferences (Bolinger 1968, Stalnaker 1984, Heim 1992, Giannakidou 1997, Farkas 2003, Villalta 2000, 2008). For purposes of simplicity, we 
Epistemics and attitudes

adopt Villalta's (2000, 2008) particular proposal, according to which attitudes that select for the subjunctive radically differ from other attitudes in the way they combine with their complements. Such attitudes involve a comparative semantics, where the complement clause is compared to a set of contextual alternatives, given a preference scale provided by the attitude.

Some empirical motivation underlying a comparative semantics is the seemingly non-monotonic behavior of verbs like want, in contrast to verbs like think, as illustrated below. A comparative semantics can derive the lack of inference in (31a) by having want express a preference for a quick death over a slow one in the first sentence, and a death over a non death in the second.

(31) a. I want to die quickly $\nRightarrow$ I want to die.

b. I believe that I will die quickly $\Longrightarrow$ I believe that I will die.

Further evidence comes from the fact that verbs expressing desires can be modified by degree modifiers, unlike verbs of acceptance (e.g., what I want the most is for Mary to leave vs. \#what I believe the most is that Mary left) (cf. Villalta 2008 and references therein).

A comparative semantics for desideratives and directives provides a way for such attitudes to combine with their complements without having to quantify over worlds consistent with an information state. By combining such a proposal with a proposal about epistemics like Yalcin's, we can derive the incompatibility between epistemics - which describe an information state - and non-representational attitudes - which do not.

\subsubsection{Villalta (2000, 2008)}

Villalta (2000, 2008) argues that attitudes like want involve a comparative semantics of contextually-provided alternatives, where the proposition expressed by the complement is ordered with respect to these alternatives. ${ }^{7}$ In the lexical entry below adapted from Villalta, want carries an index $C$

7 This lexical entry is further modified in Villalta 2008. First, Villalta adds a definedness condition according to which the contextual alternatives have to be included in the subject's doxastic alternatives. We will propose that this is not strictly true for want, but is true for hope (cf. footnote 13). Second, Villalta's final lexical entry is reformalized as to include a degree argument. Since it is irrelevant to our purposes, we keep the original version for simplicity. 
that stands for a variable anaphoric to a contextually-determined set of propositions (cf. Rooth 1985, von Fintel 1994):

$\llbracket$ want $_{C} \rrbracket^{c, w, g}=\lambda p \cdot \lambda x . \forall q \in g(C) \backslash p:\left[p>_{D E S_{x, w}} q\right]$

where $D E S_{x, w}$ is defined as follows:

a. for any $w, w^{\prime}, w^{\prime \prime}: w^{\prime}>_{D E S_{x, w}} w^{\prime \prime}$ iff $w^{\prime}$ is more desirable to $x$ in $w$ than $w^{\prime \prime}$

b. for any $p, q \subseteq W: p>_{D E S_{x, w}} q$ iff $\forall w^{\prime \prime} \in q$ : $\left[\exists w^{\prime} \in p:\left[w^{\prime}>_{D E S_{x, w}}\right.\right.$ $\left.\left.w^{\prime \prime}\right]\right]$ and $\exists w^{\prime} \in p:\left[\forall w^{\prime \prime} \in q:\left[w^{\prime \prime} \ngtr_{D E S_{x, w}} w^{\prime}\right]\right]$

We will generally assume that the set of alternatives is an exhaustive list of mutually exclusive possibilities. In the remainder of this paper, we will assume that $\mathrm{g}(\mathrm{C})=\{\psi, \neg \psi\}$, the set of alternatives assumed by Heim (1992). This assumption will allow us to simplify the presentation of the analysis of emotive doxastics and dubitatives offered in section 4. Additionally, Rubinstein (2012) argues that the data Villalta offers in support of an enriched alternative set can be handled with Heim's more restrictive set. ${ }^{8}$

\subsection{Explaining the distribution}

Recall that epistemics can only appear in complement of attitudes of acceptance, i.e., attitudes said to be correct whenever the proposition expressed by their complement is true (Stalnaker 1984). They cannot appear under desideratives or directives:

(33) a. John \{believes, argues, assumed\} that Mary has to be the murderer.

b. *John \{wants; ordered\} Mary to have to be the murderer.

We assume a Hintikkan semantics for attitudes of acceptance. Using the Yalcinian lexical entries for must and believe in (34), we see in (35) that the epistemic ends up quantifying directly over the information state determined by this set of propositions, as shown in section 3.1:

8 Thanks to an anonymous reviewer for pointing us to Rubinstein 2012. Villalta argues that subjunctive-taking attitudes are focus-sensitive operators which constrain $g(C)$ to lie in the focus-value of the subjunctive complement. Given Rubinstein's arguments, we leave adjudicating the issue of focus-sensitivity to future research. Our proposal in section 4 is compatible with Villalta's richer set, but we are not dependent on it, nor on the claim that this set is necessarily tied to focus. 
Epistemics and attitudes

（34） a. $\llbracket$ believe $\phi \rrbracket^{c, w, S, g}=\lambda x \forall w^{\prime} \in S^{\prime}:\left[\llbracket \phi \rrbracket^{c, w^{\prime}, S^{\prime}, g}=1\right]$, where $S^{\prime}=D O X_{x, w}$

b. $\llbracket$ must $\phi \rrbracket^{c, w, S, g}=1$ iff $\forall w^{\prime} \in S:\left[\llbracket \phi \rrbracket^{c, w^{\prime}, S, g}=1\right]$

(35) a. 【John believes that Mary must be the murderer $\rrbracket^{c, w, S, g}=1$ iff

b. $\forall w^{\prime} \in D O X_{j, w}:\left[\forall w^{\prime \prime} \in D O X_{j, w}:\right.$ [Mary is the murderer $\left.\left.\left(w^{\prime \prime}\right)\right]\right]$ $\equiv$

c. $\forall w^{\prime \prime} \in D O X_{j, w}:$ [Mary is the murderer $\left(w^{\prime \prime}\right)$ ]

d. In all of John's doxastic alternatives, Mary is the murderer.

The lexical entry in (32) is silent on how want updates the information state parameter. We are proposing that representational attitudes alone provide an information state; indeed, we propose that to be representational is to provide an information state, and vice versa. To capture non-representational attitudes' inability to provide an information state within Yalcin's framework, we will assume that non-representationals update the information state parameter by setting it to the empty set. ${ }^{9}$

$$
\llbracket \text { want } \phi \rrbracket^{c, w, S, g}=\lambda x \cdot \lambda w^{\prime} . \llbracket \phi \rrbracket^{c, w^{\prime}, \emptyset, g}>_{D E S_{x, w}} \lambda w^{\prime} . \neg \llbracket \phi \rrbracket^{c, w^{\prime}, \emptyset, g}
$$

Logically speaking, this move will render propositions containing true embedded universal and existential epistemics tautologous and contradictory, respectively. If we assume alongside Geurts (2005) that epistemics presuppose that their modal bases are non-trivial, we will render such cases infelicitous. ${ }^{10}$

9 In Hacquard 2010, this is done via a notion of strict locality: the epistemic must be anchored to the nearest attitude. If the attitude is non-representational, undefinedness ensues.

10 There is another, potentially simpler route to infelicity. If non-representational attitudes simply failed to update the information state parameter, embedded epistemics would be anaphoric to the last representational attitude. Then when the complement of want, $\phi$, is modalized, $\lambda w^{\prime} \llbracket \phi \rrbracket^{c, w^{\prime}, S, g}$ will either be trivially true or trivially false (cf. footnote 15 ). Therefore a standard comparison will compare a tautology to a contradiction. An anonymous reviewer asks why this wouldn't already predict the infelicity of these sentences, without needing to reset the information state parameter. This is eminently reasonable. Indeed the literature on preference orderings argues that preference alternatives must be non trivial and comprise a disjoint cover over the contextual set of worlds (cf. Hansson 2001). However, as discussed in section 4.1, Falaus (2010) has demonstrated that Romanian epistemic indefinites are not licensed in desiderative attitudes. If we assume that epistemic indefinites are sensitive to the information state parameter, then we can explain this fact. We will see how to avoid contradictions and tautologies with the preference component of emotive doxastics in section 4.1.2. 
（37） a. $\llbracket$ might $\phi \rrbracket^{c, w, S, g}$ undefined if $S=\emptyset$;

if defined $=1$ iff $\exists w^{\prime} \in S:\left[\llbracket \phi \rrbracket^{c, w^{\prime}, S, g}=1\right]$.

b. $\llbracket$ must $\phi \rrbracket^{c, w, S, g}$ undefined if $S=\emptyset$;

if defined $=1$ iff $\forall w^{\prime} \in S:\left[\llbracket \phi \rrbracket^{c, w^{\prime}, S, g}=1\right]$.

Given (36) and (37), when the attitude predicate is a desiderative or directive, an embedded epistemic will inherit a trivial modal base, yielding an infelicitous sentence. Consider (38a) below, whose logical form contains the embedded claim in (38b). The information state supplied by the desiderative is empty, clashing with the non-triviality presupposition of the semi-modal have to, as shown in (38c).

(38) a. John wants Mary to have to be the murderer.

b. have to [ Mary be the murderer]

c. $\llbracket(38 \mathrm{~b}) \rrbracket^{c, w, \emptyset, g}=\llbracket$ have to $\rrbracket^{c, w, \emptyset, g}\left(\lambda w^{\prime} \llbracket\right.$ Mary be the murderer $\left.\rrbracket^{c, w^{\prime}, \emptyset, g}\right)$ $=\#$ because $\llbracket$ have to $\rrbracket^{c, w, \emptyset, g}=\#$

To sum up, attitudes of acceptance (doxastics, argumentatives, semifactives ...) can embed epistemics because they have a representational semantics: they supply an information state that epistemics are anaphoric to. Desideratives and directives, on the other hand, are non-representational, but instead have a comparative semantics. Because of their non-representationality, they cannot provide an information state that epistemics are anaphoric to, and hence do not allow them in their complements.

\subsection{Escape hatches, mystery novels, and filing cabinets}

As we mentioned in section 2.3, embedded epistemics in complements of desideratives and directives may not be completely impossible. Consider the following example:

(39) John wants Paul to have to be the murderer [according to the police report].

John prefers that in all worlds compatible with the police report Paul is the murderer to other contextual alternatives.

With respect to the proposal above, what is special about (39) is that the epistemic quantifies not over what is true in worlds where John's desires are fulfilled, but the doxastic state of a (potentially covert) attitude. In that sense, (39) contradicts not the generalization about epistemics being dependent 
Epistemics and attitudes

on an information state, but the syntactic requirement that this information state be anaphoric to that of the attitude. In cases where there is an overt conversational background expressed by an 'according to $X$ ' phrase, this is unsurprising; the 'according to' phrase itself introduces an information state, whose content in (39) is the police report. But, as we noted in section 2.3, this kind of reading may happen without an overt 'according to' phrase.

Cases like (39) are not particular to non-representational attitudes. Kratzer (2009), for example, considers doxastic attitude environments in which epistemics are interpreted relative to a non-attitude holder perspective. Her example concerns a scenario in which evidence in a filing cabinet is made salient (note that while the example in (40) involves a $1^{\text {st }}$ person indexical attitude holder, a $3^{\text {rd }}$ person case is also acceptable):

(40) Scenario: Nobody among us has had access to the information in this filing cabinet, but we know that it contains the complete evidence (including possibly forged evidence) about the murder of Philip Boyes and narrows down the set of suspects. We are betting on who might have killed Boyes according to the information in the filing cabinet. Harriet, who is innocent, says: I think I might have killed him. (Kratzer 2009), pg. 33.

Kratzer concludes that modals' quantificational domains are usually, but not always given by the embedding attitude. Thus, the sentence 'Harriet thinks she might have killed him' would have the LF in (41a) in most contexts, but the one in (41b) in scenario (40):

(41) a. In some world compatible with Harriet's beliefs [S], Harriet killed Boyes.

b. In all worlds compatible with Harriet's beliefs [S], there is some world compatible with the filing cabinet's information in which Harriet killed Boyes.

Hence, we see that epistemics can sometimes be licensed when the context makes a body of information extremely salient, such as a filing cabinet, or a mystery novel. Crucially, when epistemics are acceptable in complements of desideratives or directives, the modal isn't about the knowledge or doxastic state of the attitude holder, the way it is with verbs of acceptance. Instead, epistemics are only possible to the extent a third party's information state (such as a police report or the content of a mystery novel) is available, by using a strategy in principle available with all attitude verbs. 
There are two ways our proposal for the licensing of epistemics could be extended to account for cases like (39) and (40). The first would be to assume that they involve covert according to $X$ information state shifting operators. The second would be to adopt Kratzer's analysis, according to which these readings arise from a free variable over a contextually salient information state. In the remainder of this paper, we will be agnostic on which analysis is superior; more empirical work is necessary to understand the restrictions on such readings.

\section{Emotive doxastics and dubitatives}

We have seen that epistemics can't appear in complements of desideratives and directives, but that they are acceptable under attitudes of acceptance. This dichotomy correlates with mood selection in Romance: epistemics can't appear in complements of those verbs that select for subjunctive. However, as we saw in section 2, some verbs, namely emotive doxastics and dubitatives, show a mixed behavior: they allow possibility epistemics but not necessity ones. Interestingly, this is precisely the class of predicates that shows mixed mood selection behavior at the cross-linguistic level: while they tend to select for subjunctive, French hope allows the indicative as well ${ }^{11}$, and Romanian fear and doubt select for indicative exclusively (cf. Farkas 1992). Why should this be? What is the relationship between mood selection, epistemics and attitudes? It can't be that epistemics are incompatible with subjunctive mood. As we saw, epistemics can be found in certain subjunctive complements: (i) they are acceptable in the complement of Italian think; (ii) possibility epistemics are acceptable in (subjunctive) complements of emotive doxastics and dubitatives; (iii) epistemics are acceptable even in (subjunctive) complements of desideratives, so long as they are anchored to an intervening conversational background. In terms of the quantificational asymmetry, while there is an overall preference for the possibility modal across all attitude verbs (cf. Appendix for details), this preference is exacerbated in complements of emotive doxastics and dubitatives.

We argued in section 3 that epistemics track representationality: if they are acceptable, then the embedding attitude is representational: it describes an information state. If epistemics are unacceptable, then the embedding attitude lacks such an information state: it is not representational. According to Villalta (2000, 2008), subjunctive selection tracks preferences: all attitudes

11 Exclusively for some speakers (Philippe Schlenker, p.c.). 
Epistemics and attitudes

that select for subjunctive mood have a comparative semantics, where what changes from attitude to attitude is the scale of comparison (e.g., scale of desires for hope and want, scale of likelihood for doubt ...).

Does subjunctive mood always track preferences? Recall that Italian think selects for the subjunctive. However, it isn't clear that it involves a preference component unlike its counterparts in other Romance languages. For Villalta, this is not an issue, since she focuses exclusively on Spanish. Here, we remain agnostic about what exactly underlies the correlation between subjunctive mood and preferences, and assume that subjunctive is an imperfect indicator of preferences. ${ }^{12}$

We thus have two different diagnostics for the semantics of attitude verbs: epistemics track representationality, subjunctive mood, preferences (perhaps imperfectly). However, preferences and representationality need not be mutually exclusive: we may thus expect to find attitudes with both a representational and a preference component. We might further expect such attitudes to license epistemics, and still select for subjunctive mood. We propose that this is precisely what occurs for emotive doxastics and dubitatives.

We will argue that epistemic possibility modals are good in complements of emotive doxastics due to their representational component. What rules out necessity epistemics will be an incompatibility between the certainty of such modals, and the uncertainty associated with having several alternatives, which preferences range over. We turn to emotive doxastics in section 4.1 and dubitatives in section 4.2.

\subsection{The hybrid semantics of emotive doxastics}

Hope and fear clearly have a preference component: they express, respectively, preference and dispreference for a state of affairs. Nonetheless, they pattern with representational attitudes (and not desideratives/directives) on a range of pragmatic, semantic, and syntactic tests (Truckenbrodt 2006, Scheffler 2008, Falaus 2010). One illustrative example comes from the contrast discussed in section 1. (Scheffler 2008), attributing the example to Hubert

12 An anonymous reviewer points out that promise disallows epistemics and seems to intuitively track preferences, yet it selects the indicative in Romance. We assume that promise is a nonrepresentational attitude, which is why it disallows epistemics. Its preference component is imperfectly reflected by the mood it selects. 
Truckenbrodt, points out that emotive doxastics may be used to felicitously respond to a question, unlike desideratives like want:

(42) A: Kommt Peter heute? (Scheffler 2008) comes Peter today

'Is Peter coming today?'

B: Ich hoffe/“will, dass er heute kommt. I hope/*want that he today comes 'I hope/*want that he is coming today'

Scheffler argues that the felicity with hope is due to its doxastic component: B asserts with hope $p$ that $p$ is a possibility, hence providing a partial answer to A's question (cf. also Portner 1992, who argues that hope requires its subject to believe the complement to be possible).

In addition to asserting that $p$ is a doxastic possibility, hope $p$ and fear $p$ convey that $\neg p$ is also possible. That is, they convey uncertainty about $p$ 's truth, and are therefore infelicitous with statements entailing that the attitude holder is certain about $p$, as shown in (43a). This crucially contrasts with desideratives, which may be used to communicate merely the preferences of the attitude holder, as in (43b).

(43) It is raining.

(Scheffler 2008)

a. \# I hope it is raining/\#that is what I hope.

b. $\checkmark$ I want it to be raining/ $\checkmark$ that is what I want.

Similarly, while hope $p$ and fear $p$ are incompatible with an assertion of the certainty of $\neg p$ as in (44a), desideratives are compatible (44b). In short, emotive doxastics require relevant alternatives to be doxastic possibilities, but desideratives do not (pace Heim and following ${ }^{13}$ ).

(44) It isn't raining.

a. \# I hope it is raining/\#that is not what I hope.

b. $\checkmark$ I want it to be raining/ $\checkmark$ that is not what I want.

13 Specifically, we assume the following: (a) the alternatives for hope must be doxastic possibilities, (b) those for wish are not doxastic possibilities, and (c) want imposes no constraint. Regardless of whether wish's counter-to-belief requirement is an entailment or a presupposition, <want, wish $>$ form a scale, and a Heimian want which talks about what is believed to be possible is a result of a scalar inference. 
Epistemics and attitudes

Falaus (2010) documents a similar hope vs. want contrast for the Romanian epistemic indefinite vreun, which is illicit in the complement of want, but licit in the complement of hope as well as doxastic attitudes more generally:

*Vreau să iau vreun zbor spre Paris. (Falaus 2010) want.1SG SUBJ take.1SG VREUN flight to Paris

'I want to take some flight to Paris.'

(46) Sper să găsesc vreun zbor spre Paris. (Falaus 2010) hope.1SG SUBJ find.1SG VREUN flight to Paris

'I hope to find some flight to Paris.'

Emotive doxastics seem to show the most variability in terms of mood selection, as discussed above. This instability of mood selection seems to reflect the hybrid nature of these verbs. As mentioned earlier, mood selection in Romance correlates with other syntactic reflexes, such as preposing or V2 complements in German. Hope and fear pattern with the representationals in allowing such complements (Truckenbrodt 2006, Scheffler 2008).

We thus see that while emotive doxastics share a preference component with desideratives, they also pattern with attitudes of acceptance in various ways, suggesting that their semantics involves a representational component as well.

\subsubsection{Emotive doxastics and epistemics}

In the previous section, we have shown that emotive doxastics seem to convey three inferences about the attitude holder: a) that she takes $\phi$, the proposition expressed by the complement, to be possible, b) that she prefers $\phi$ to its contextual alternatives and c) that each of the contextual alternatives are possible for her, and thus that she is uncertain about the truth of $\phi$. We propose that the first inference is responsible for the licensing of epistemics in emotive doxastic complements, and the uncertainty inference for their allergy to epistemic necessity modals.

That infelicity of necessity epistemics follows from the element of uncertainty in the doxastic component of these attitudes. As we just saw, hope and fear (unlike true desideratives such as want) require that the attitude holder is truly uncertain about which alternative is true: the alternative expressed by the complement clause must be one of several doxastic possibilities. As a 
result, any claim of epistemic necessity will be infelicitous, as it will require that there is only one relevant doxastic possibility.

To see this informally, consider the instantiation in (47) of the possibility inference:

(47) a. a hopes ${ }_{C}$ that $\mathrm{p} \Longrightarrow$ a believes might $\mathrm{p}$

b. $\exists w^{\prime} \in D O X_{a, w}: p\left(w^{\prime}\right)=1$

doxastic assertion

c. $\neg \forall w^{\prime} \in D O X_{a, w}: p\left(w^{\prime}\right)=1$

uncertainty condition

Condition (47a) requires that hoping entails 'believing might', or that the attitude holder's doxastic state is compatible with $p$ (47b). Because hope expresses uncertainty, however, the attitude holder cannot be certain about the truth of the complement clause: $p$ cannot be true throughout all of her doxastic alternatives $(47 \mathrm{C})$.

Now, if the complement of hope is a modal statement itself, which expresses necessity, such as in (48a), we obtain the doubly quantified inference in (48b), with hope providing the first layer of (existential) quantification over the doxastic state, and must providing the second layer of (universal) quantification over that same doxastic state. By vacuous quantification, the inference is equivalent to (48c), which states that John is certain about the truth of $p$.

(48) a. John hopes that must $p$

b. $\exists w^{\prime} \in D O X_{j, w}:\left[\forall w^{\prime \prime} \in D O X_{j, w}:\left[p\left(w^{\prime \prime}\right)=1\right]\right]$

c. $\forall w^{\prime \prime} \in D O X_{j, w}:\left[p\left(w^{\prime \prime}\right)=1\right]$

If we assume that hope's uncertainty condition is about the truth of $p$ (which we will justify in the next section), then we will generate a contradiction as desired ((47c) vs. (48c)). In contrast, both embedded unmodalized $p$ and might $p$ yield the doxastic inference might $p$, which does not run afoul of the uncertainty inference. Thus, the possibility and uncertainty inferences of emotive doxastics manage to semantically capture what might look like a form of agreement: must is bad under emotive doxastics, and might is good.

Turning to their preference component, emotive doxastics express uncertainty with respect to an issue raised by their complement (e.g., Is it raining?). The contextual alternatives correspond to the ways this uncertainty could be resolved, i.e., the cells of the partition that the issue imposes over the doxastic state. What we take the preference component to do is express the attitude holder's preference for how this uncertainty gets resolved, which 
Epistemics and attitudes

means indicating a preference between various subsets of her doxastic state. If John hopes that it is raining, John is uncertain about whether it is raining or not: it is raining in some of his doxastic alternatives, and it is not raining in others. His preference is for a resolution of the uncertainty in favor of rain. That is, John prefers those doxastic alternatives in which it is raining over those in which it isn't. Or, as we will put it, the subset of his doxastic alternatives that verify rain are more desirable to him than those that falsify them. ${ }^{14}$

We will propose that modalized complements raise the same issue as unmodalized ones. That is, regardless of whether John hopes that it is, might be, or must be raining, it is still the case that John's doxastic state is uncertain about whether it is raining. Correspondingly, we will propose that, regardless of the modalization, the same alternatives get compared, and thus John prefers doxastic alternatives verifying rain to those that falsify it. We now provide a formal treatment of the above proposal sketch. We start with the preference component in 4.1.2, the uncertainty inference in 4.1.3 and will put it all together in 4.1.4.

\subsubsection{Preference component}

One of the key formal tasks of this section is to define the notions of verifiers and falsifiers in a way that makes them the same regardless of the modal status of $\phi$, the complement of an emotive doxastic. We will do this by requiring verifiers and falsifiers to resolve the uncertainty in the doxastic state; that is, the verifiers/falsifiers will need to be certain (or settled) about the issue raised by $\phi$.

If $\phi$ is an unmodalized proposition, then the $\phi$-verifying worlds in information state $S$ are those in $S \cap \phi$. Note that any subset of $S \cap \phi$ is certain about $\phi$ as well. In contrast, any modalized $\phi$ of the form might $p$ or must $p$ will be a proposition equivalent to a tautology or contradiction, because modalized statements are not world-relative but information state-relative. ${ }^{15}$ We thus cannot determine $\phi$-verifiers by simple intersection with $S$. Instead,

14 We thank an anonymous reviewer for inspiring this analysis.

15 Because in an information state relative-framework modals are not world-relative, a proposition of the form $\lambda w \cdot \exists w^{\prime} \in S:\left[\llbracket p \rrbracket^{c, w^{\prime}, S, g}=1\right]$ will only be able to yield trivial propositions: trivially true if there is a world in $S$ in which $p$ is true, or trivially false if there isn't. This is not a problem when the complement composes with an attitude. The problem arises when a proposition needs to be extracted and stand alone, as when needed to be compared to other propositions. 
because $\phi$ is information state-relative, $\phi$-verification must be defined in information state-relative terms.

We will say that $S^{\prime}$ is a $\phi$-verifier iff (i) $\phi$ is true relative to $S^{\prime}$ and (ii) $S^{\prime}$ is certain about $\phi$. Intuitively, $S^{\prime}$ is certain about $\phi$ iff $\phi$ 's truth value does not change with (monotonically) increasing information. As increasing information narrows down the information state, certainty means that $\phi$ 's truth relative to all of the subsets of $S^{\prime}$ is the same as that relative to $S^{\prime}$ itself.

Suppose $\phi$ is of the form might $p$. If $\phi$ is true relative to $S^{\prime}$, it contains $p$ worlds. It may also contain $\neg p$ worlds, in which case $S^{\prime}$ would be uncertain about $\phi$ because in those subsets of $S^{\prime}$ where $\neg p$ holds, $\neg$ might $p$ (i.e., $\neg \phi$ ) holds as well. ${ }^{16}$ Suppose $\phi$ is of the form must $p$. Then, by definition, if $\phi$ is true relative to $S^{\prime}$, then there can be no $\neg \phi$ worlds in $S$ ', and therefore it is certain about $\phi$. Thus, for $S^{\prime}$ to be a $\phi$-verifier, it must be the case that $\phi$ is not only true relative to $S^{\prime}$, but relative to all of its subsets ( $S^{\prime}$ is certain about $\phi)$. Our definition of $\phi$-verifier is formally expressed in (49):

(49) $\phi$-verifiers in $S$ (to be revised) $=\lambda S^{\prime} . S^{\prime} \subset S \wedge \forall S^{\prime \prime} \subset S^{\prime}:\left[\llbracket \phi \rrbracket^{c, w, S^{\prime \prime}, g}=1\right]$

The above definition only works for modalized $\phi$ because unmodalized propositions are not information state-relative. However, we saw at the outset of this subsection that an information state $S^{\prime}$ is a certain verifier for a nonmodal $\phi$ iff $S^{\prime} \subset \phi$. We can use this fact to provide a unified definition for $\phi$-verifiers in (50):

(50) $\phi$-verifiers in $S=\lambda S^{\prime} . S^{\prime} \subset S \wedge \forall S^{\prime \prime} \subset S^{\prime}: \forall w^{\prime} \in S^{\prime \prime}:\left[\llbracket \phi \rrbracket^{c, w^{\prime}, S^{\prime \prime}, g}=1\right]$

When $\phi$ is modalized, the universal quantifier over worlds is vacuous because $\phi$ is not world-relative. Thus, based on (50), regardless of whether $\phi$ is $p$, might $p$, or must $p$, the $\phi$-verifiers are the powerset of $S \cap p$ (excluding $\emptyset)$. This is illustrated in Figure 3.

As mentioned in 4.1.1, we will propose that the preference component compares verifiers (as defined in (50)) based on the alternatives in $g(C)$. Recall that Villalta's semantics for want says that $\phi$ is more desirable than any other alternative in $g(C)$. Assuming that $g(C)=\{\phi, \neg \phi\},{ }^{17}$ we will

16 Because modals quantify directly over an information state, the facts in (1) hold:

(i) a. If $S \subset p$, then $\llbracket$ might $p \rrbracket^{c, w, S, g}=\llbracket$ must $p \rrbracket^{c, w, S, g}=1$

b. If $S \subset \neg p$, then $\llbracket \neg$ might $p \rrbracket^{c, w, S, g}=\llbracket \neg$ must $p \rrbracket^{c, w, S, g}=1$

17 If $g(C)=\{\phi, \psi, \rho\}$, hope states that the $\phi$-verifiers are better than both the $\psi$-verifiers and the $\rho$-verifiers. 
Epistemics and attitudes

compare the $\phi$-verifiers and $\phi$-falsifiers (the $\neg \phi$-verifiers). Thus, for $\phi \in\{q$, might q, must q\}, 'a hopes that $\phi$ ' has the following preference component:

(51) a hopes ${ }_{C}$ that $\phi$

$\phi$-verifiers $>_{D E S_{a, w}} \phi$-falsifiers iff

$\lambda S^{\prime} . S^{\prime} \subset S \wedge \forall S^{\prime \prime} \subset S^{\prime}:\left[\forall w^{\prime} \in S^{\prime \prime}:\left[\llbracket \phi \rrbracket^{c, w^{\prime}, S^{\prime \prime}, g}=1\right]\right]>_{D E S_{a, w}}$

$\lambda S^{\prime} . S^{\prime} \subset S \wedge \forall S^{\prime \prime} \subset S^{\prime}:\left[\forall w^{\prime} \in S^{\prime \prime}:\left[\llbracket \phi \rrbracket^{c, w^{\prime}, S^{\prime \prime}, g}=0\right]\right]$

Whereas the comparison in want is between propositions, the comparison for emotive doxastics in (51) is between sets of propositions (i.e., subsets of $p o w^{2}(W)$ ). We will now show that under a natural ordering between these sets, the comparison in (51) is true iff $S \cap p>_{D E S_{a, w}} S \cap \neg p$. We construct an ordering over this space in a similar fashion to how we order propositions in terms of the basic ordering over worlds: one set is better than another if all propositions in the second set are bettered by some (potentially distinct) proposition in the first, but not vice versa. This is given in (52):

(52) $>_{D E S_{x, w}}$ is defined over predicates of information states as follows:

For any $P, Q \in p o w^{2}(W), P>_{D E S_{x, w}} Q$ iff

$\forall q \in Q:\left[\exists p \in P:\left[p>_{D E S_{x, w}} q\right]\right]$, and

$\exists p \in P:\left[\forall q \in Q:\left[q \ngtr_{D E S_{x, w}} p\right]\right]$

For example, let $P=\{$ that it's raining, that Mary is innocent $\}$ and $Q=\{$ that it's not raining, that Paul is guilty\}. Then $P>_{D E S_{x, w}} Q$ iff both propositions in $Q$ are bettered by either that it's raining or that Mary is innocent, but both propositions in $P$ are not bettered by one in $Q$. The proposition ordering $p>_{D E S_{x, w}} q$ in (32) is upward monotone for $p$ and downward monotone for

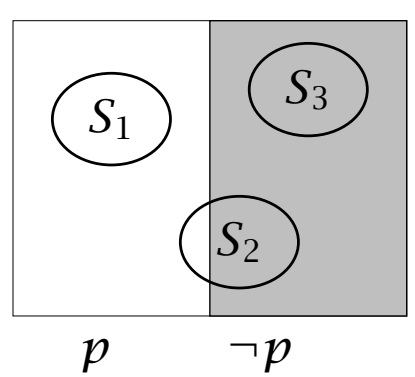

$p$, might $p$ and must $p$ are all true and certain in $S_{1}$.

$p$, might $p$ and must $p$ are all false and certain in $S_{3}$.

$p$ and must $p$ are false and uncertain in $S_{2}$; might $p$ is true but uncertain in $S_{2}$.

$S_{1}$ is a verifier for $p$, might $p$ and must $p$. $S_{3}$ is a falsifier for $p$, might $p$ and must $p$.

Figure $3 \phi$-verifiers and $\phi$-falsifiers 
$q .{ }^{18}$ These facts are responsible for yielding the equivalence that pow ( $S \cap$ $p)>_{D E S_{a, w}} \operatorname{pow}(S \cap \neg p)$ iff $S \cap p>_{D E S_{a, w}} S \cap \neg p$ shown at the end of (51). ${ }^{19}$

Thus, concretely speaking, 'a hopes p', 'a hopes might p' and 'a hopes must p' all yield the inference that a prefers $p$-verifying doxastic alternatives to $\neg p$-verifying doxastic alternatives. In short, they all yield 'a wants q' (when restricted to her doxastic information state), making good on one half of emotive doxastics' hybridity.

\subsubsection{Uncertainty}

What remains is to discuss the doxastic component of emotive doxastics. We have proposed that these attitudes express two doxastic inferences. First, they assert that $\phi$ is doxastically possible. This is the following straightforward claim:

(53) a. a hopes $C$ that $\phi$

b. $\exists w^{\prime} \in S^{\prime}:\left[\llbracket \phi \rrbracket^{c, w^{\prime}, S^{\prime}, g}=1\right]$, where $S^{\prime}=D O X_{a, w} \quad$ doxastic assertion

By the logic of vacuous quantification, if $\phi$ is might $p$ or unmodalized $p$, the doxastic assertion will be the same: that $D O X_{a, w} \cap p \neq \emptyset$. However, if $\phi$ is must $p$, we end up with the assertion that $D O X_{a, w} \subset \mathrm{p}$.

In addition, these attitudes require that the other contextual alternatives are live possibilities. This amounts to saying that each of the contextual alternatives has a non-trivial verifier set, which, given the discussion in 4.1.1 and $g(C)=\{\phi, \neg \phi\}$, is the following:

(54) a hopes ${ }_{C}$ that $\phi$

$\phi$-verifiers in $S^{\prime} \neq \emptyset \wedge \phi$-falsifiers in $S^{\prime} \neq \emptyset \quad$ uncertainty condition where $S^{\prime}=D O X_{a, w}$

Together, (53) and (54) predict that possibility epistemics are licit under emotive doxastics while necessity epistemics are not. The constraint in (54) requires that each alternative intersects $D O X_{a, w}$. But as the alternatives

18 This is because $q$ is always universally quantified over and $p$ is existentially quantified over. 19 As the sets under comparison are power sets, the monotonicity properties above yield the desired equivalences. In particular, $\forall r \in \operatorname{pow}(S \cap \neg q):\left[\exists t \in \operatorname{pow}(S \cap q):\left[t>_{D E S_{a, w}} r\right]\right]$ is equivalent to $\forall r \in \operatorname{pow}(S \cap \neg q):\left[S \cap q>_{D E S_{a, w}} r\right]$ by the upward monotonicity in the first operand. But by downward monotonicity in the second operand, $S \cap q>_{D E S_{a, w}} S \cap \neg q$ iff $\forall r \in \operatorname{pow}(S \cap \neg q):\left[S \cap q>_{D E S_{a, w}} r\right.$, hence these are also equivalent. 
Epistemics and attitudes

induce a partition over $D O X_{a, w}$, the doxastic assertion with must $p$ will require that no other alternative is realized in $D O X_{a, w}$.

\subsubsection{Putting it all together}

The lexical entry in (55) summarizes the components of an emotive doxastic: there is an existential doxastic assertion, ${ }^{20}$ a preference assertion and an uncertainty felicity condition:

(55) $\llbracket$ hopes ${ }_{C}$ that $\phi \rrbracket^{c, w, S, g}=\lambda x$ :

$\phi$-verifiers in $S^{\prime} \neq \emptyset \wedge \phi$-falsifiers in $S^{\prime} \neq \emptyset$. uncertainty condition

If defined $=1$ iff

$\exists w^{\prime} \in S^{\prime}:\left[\llbracket \phi \rrbracket^{c, w^{\prime}, S^{\prime}, g}=1\right] \wedge$

doxastic assertion

$\phi$-verifiers $>_{D E S_{x, w}} \phi$-falsifiers

preference assertion

where $S^{\prime}=D O X_{x, w}$ and $\phi$-verifiers in $S^{\prime}=$

$\lambda S^{\prime \prime} . S^{\prime \prime} \subset S^{\prime} \wedge \forall S^{\prime \prime \prime} \subset S^{\prime \prime}:\left[\forall w^{\prime} \in S^{\prime \prime \prime}:\left[\llbracket \phi \rrbracket^{c, w^{\prime}, S^{\prime \prime \prime}, g}=1\right]\right]$

$\phi$-falsifiers in $S^{\prime}=\neg \phi$-verifiers in $S^{\prime}$

When $\phi$ is an unmodalized complement $p$, we obtain the following:

(56) $\llbracket$ a hopes ${ }_{C}$ that $p \rrbracket^{c, w, S, g}$ is defined iff

$p$-verifiers in $S^{\prime} \neq \emptyset \wedge p$-falsifiers in $S^{\prime} \neq \emptyset$.

uncertainty condition

If defined $=1$ iff

$\exists w^{\prime} \in S^{\prime}:\left[\llbracket p \rrbracket^{c, w^{\prime}, S^{\prime}, g}=1\right] \wedge$

doxastic assertion

$p$-verifiers $>_{D E S_{a, w}} p$-falsifiers

preference assertion

where $S^{\prime}=D O X_{a, w}$ and $p$-verifiers in $S^{\prime}=$

$\lambda S^{\prime \prime} . S^{\prime \prime} \subset S^{\prime} \wedge \forall S^{\prime \prime \prime} \subset S^{\prime \prime}:\left[\forall w^{\prime} \in S^{\prime \prime \prime}:\left[\llbracket p \rrbracket^{c, w^{\prime}, S^{\prime \prime \prime}, g}=1\right]\right]=p o w\left(S^{\prime} \cap p\right)$

$p$-falsifiers in $S^{\prime}=\neg p$-verifiers in $S^{\prime}=p o w\left(S^{\prime} \cap \neg p\right)$

The following example concretely illustrates hope's semantics at work:

(57) John hopes that it is raining.

Uncertainty: There is a non-trivial subset of John's belief worlds where it is raining and a non-trivial subset where it is not raining.

Doxastic: There is a world compatible with John's beliefs where it is raining.

Preference: Rain is more desirable to John than no rain.

20 We take the doxastic component to be assertion based upon the fact that emotive doxastics can serve as answers to questions, as show in (42). 
When $\phi$ is epistemically modalized, we obtain the following components for hope that Mod $p$. Recall that the Mod $p$-verifiers will be the same as the $p$-verifiers:

(58) $\llbracket$ a hopes $_{C}$ that Mod $p \rrbracket^{c, w, S, g}$ is defined iff

$\operatorname{Mod} p$-verifiers in $S^{\prime} \neq \emptyset \wedge \operatorname{Mod} p$-falsifiers in $S^{\prime} \neq \emptyset$. uncertainty condition If defined $=1$ iff

$\exists w^{\prime} \in S^{\prime}:\left[\llbracket \operatorname{Mod} p \rrbracket^{c, w^{\prime}, S^{\prime}, g}=1\right] \wedge$

$\operatorname{Mod} p$-verifiers $>_{D E S_{a, w}} \operatorname{Mod} p$-falsifiers

doxastic assertion

where $S^{\prime}=D O X_{a, w}$ and Mod $p$-verifiers in $S^{\prime}=$

$\lambda S^{\prime \prime} . S^{\prime \prime} \subset S^{\prime} \wedge \forall S^{\prime \prime \prime} \subset S^{\prime \prime}:\left[\forall w^{\prime} \in S^{\prime \prime \prime}:\left[\llbracket p \rrbracket^{c, w^{\prime}, S^{\prime \prime \prime}, g}=1\right]\right]=p o w\left(S^{\prime} \cap p\right)$

$\operatorname{Mod} p$-falsifiers in $S^{\prime}=\neg \operatorname{Mod} p$-verifiers in $S^{\prime}=p o w\left(S^{\prime} \cap \neg p\right)$

When the modal in question is must, we get a direct contradiction between the uncertainty presupposition and the doxastic assertion. When it is might, we do not, thus deriving the quantificational force asymmetry from the lexical semantics of the emotive doxastic itself. The following example illustrates with might:

(59) John hopes that it might be raining.

Uncertainty: There is a non-trivial subset of John's belief worlds where it is raining and a non-trivial subset where it is not raining.

Doxastic: There is a world compatible with John's beliefs where it is raining.

Preference: Rain is more desirable to John than no rain.

As this is identical to (57), it shows that our semantics renders complements of emotive doxastics with possibility epistemics equivalent to those without them, amounting to a kind of 'modal concord' (cf. section 5.3). With respect to the doxastic assertion, this concord arises because the attitude and the epistemic modal quantify over the same information state. However, these two modal operators may differ in their ordering sources, which may give rise to meaning differences in context. ${ }^{21}$

21 In informal discussions, consultants have told us that using might as in (ib) indicates that the possibility of someone listening in is more remote. Note that this seems to be lexically variable; consultants report that the contrast is appreciably weaker for hope than be worried. 
Epistemics and attitudes

\subsection{Dubitatives}

Recall that dubitatives show a similar profile to emotive doxastics, admitting possibility but not necessity epistemics. We propose that this parallel profile is the result of parallel lexical semantics.

First, like emotive doxastics, dubitatives seem to convey a weak possibility assertion about an embedded proposition $p$, a fact which will derive the quantificational asymmetry. That there are non- $p$ worlds in the attitude holder's doxastic state is uncontroversial. Less obvious is the claim that $x$ doubts $p$ semantically commits $x$ to might $p$, especially in light of examples like (6o), which would be a contradiction if doubt entailed uncertainty:

(6o) John doubts that she's the murderer. In fact, he's certain she's innocent.

Given that in fact has been advanced as an implicature suspender (Sauerland 2004), (6o) suggests that the uncertainty inference we propose for doubt is a case of scalar inference. However because, which can suspend implicatures by providing logical reasons, seems to behave differently. In (61), because seems to felicitously cancel the exhaustivity inference for some, but not the uncertainty inference for doubt.

(61) a. \#John doubts that she's the murderer because he is certain she's innocent.

b. Some of them left because all of them did.

What should we make of the felicity in (6o) then? In addition to its function as an implicature suspender, in fact may also be used for cases of retraction, and we suggest that (6o) is an instance of such a use. Potential evidence for this conclusion comes from (62), which asserts the possibility inference we claim is encoded in doubt (and hence is not a case of implicature suspension).

(i) a. John is worried that someone is listening in.

b. John is worried that someone might be listening in.

One explanation for this would be that the doxastic assertion quantifies over a subset of the doxastic state while might quantifies over the whole doxastic state. We leave more detailed investigation of this phenomenon to future research. 
(62) John thinks that it's possible that she's the murderer, but that it's very unlikely. \#(In fact,) he's certain she's innocent.

As this sentence is felicitous only with in fact, it suggests that its role is to recalibrate the speaker's commitment to the previous sentence. ${ }^{22}$

As with emotive doxastics, our proposal is that the uncertainty inference arises from the nature of the preference component. According to Villalta, doubt (in Spanish) has a preference component, in the form of a likelihood scale. If John doubts that $p$, then $p$ is less likely than (at least some) contextually-available alternatives. However, given our discussion above, all of the alternatives must be live doxastic possibilities.

The above discussion sketches a lexical semantics for doubt very similar to that of hope above: a doxastic assertion of possibility, a likelihood comparison of the information state predicate and its complement (via the PROBABILITY ordering ${ }^{23}$ ), and an inference of uncertainty:

(63) $\llbracket$ a doubts $_{C}$ that $\phi \rrbracket^{c, w, S, g}$ is defined iff

$\phi$-verifiers in $S^{\prime} \neq \emptyset \wedge \phi$-falsifiers in $S^{\prime} \neq \emptyset$. uncertainty condition

If defined $=1$ iff

$\exists w^{\prime} \in S^{\prime}:\left[\llbracket \phi \rrbracket^{c, w^{\prime}, S^{\prime}, g}=1\right] \wedge$

doxastic assertion

$p$-falsifiers $>_{P R O B a, w} p$-verifiers

preference assertion

where $S^{\prime}=D O X_{a, w}$ and $\phi$-verifiers in $S^{\prime}=$

$\lambda S^{\prime \prime} . S^{\prime \prime} \subset S^{\prime} \wedge \forall S^{\prime \prime \prime} \subset S^{\prime \prime}:\left[\forall w^{\prime} \in S^{\prime \prime \prime}:\left[\llbracket p \rrbracket^{c, w^{\prime}, S^{\prime \prime \prime}, g}=1\right]\right]=p o w\left(S^{\prime} \cap p\right)$

$\phi$-falsifiers in $S^{\prime}=\neg \phi$-verifiers in $S^{\prime}$

Hence the example in (63) yields the following assertions:

(64) John doubts that it is raining.

Uncertainty: There is a non-trivial subset of John's belief worlds where it is raining and a non-trivial subset where it is not raining.

Doxastic: There is a world compatible with John's beliefs where it is raining.

Preference: No rain is more likely to John than rain.

22 Paul Portner (p.c.) suggests that the predicate of certainty in (6o) is being interpreted w.r.t. a different ordering source than doubt; thus in fact may signal the readjustment of pragmatic factors quite generally.

23 Yalcin (2010) and Lassiter (2010) both note that the better possibility relation in Kratzer 1991 results in questionable inferences when measures should be additive, as is arguably the case for likelihood measures. However, as noted by Partee (p.c. in Villalta 2008), it is possible to construct an additive ordering from a non-additive ordering by direct counting, and doing so is completely compatible with our present proposal. 
Epistemics and attitudes

Given the similar semantics provided, dubitatives will license possibility epistemics in a parallel fashion and likewise forbid necessity epistemics. ${ }^{24}$

\section{Alternative explanations for the data}

\subsection{Subjunctive allergy}

Our Romance survey shows that the attitude predicates that disallow epistemics are those that select for subjunctive mood in the core Romance languages: desideratives and directives disallow all epistemics; emotive doxastics and dubitatives disallow necessity epistemics. Could it be that epistemics are simply incompatible with subjunctive mood, whether for syntactic, morphological or semantic reasons?

The first hint that epistemics are in principle compatible with subjunctive comes from Italian pensare (think), which unlike the rest of Romance selects for subjunctive rather than indicative mood. As with its counterparts in other Romance languages, epistemics are acceptable in the complement of pensare:

Gianni pensa che Maria debba aver conosciuto il suo
Gianni thinks that Maria must-SUBJ have known her
assassino.
killer

Furthermore, if the problem was really mood allergy, we might expect that languages that do not differ in the mood selection of their attitude predicates may not show the same ban against epistemics in complements of desideratives and directives. We already observed in (2) that the same ban occurs in English. Although detailed follow-up is needed, according to three informants, the same contrast is observed in German attitude verbs: they

24 In our survey results, epistemic necessity modals in the complement of doubt were rated higher than those in the complements of hope or fear (although not that high overall). We have confirmed informally that some speakers find them acceptable. However, these speakers consistently report scenarios involving what appears to be metalinguistic negation (as does an anonymous reviewer): They require contrastive focus on the modal as well as a prior context in which someone has asserted, questioned or argued for the embedded proposition:

(i) A: Mary must be the murderer.

B: She MIGHT be the murderer, but I doubt that she MUST be the murderer.

Whether this metalinguistic form of doubt involves uncertainty is something we leave for future research. 
allow epistemics in complements of doxastics, disallow them in complements of desideratives, and allow possibility but not necessity epistemics in complements of emotive doxastics. Note that, unlike in English, desideratives in German take the same finite complements as doxastics.

(66) Der Jan denkt, dass die Maria ihren Moerder gekannt haben The Jan thinks, that the Maria her murderer known have \{muss/koennte\}. \{must/could\}

'John thinks that Maria \{must; may\} have known her killer'

(67) \#Der Jan will, dass die Maria ihren Moerder gekannt haben The Jan wants, that the Maria her murderer known have \{muss/koennte\}. \{must/could

'John wants that Maria \{must; may\} have known her killer'

(68) Der Jan hofft, dass die Maria ihren Moerder gekannt haben The Jan hopes, that the Maria her murderer known have koennte.

could

'John hopes that Maria may have known her killer'

(69) \#Der Jan hofft, dass die Maria ihren Moerder gekannt haben The Jan hopes, that the Maria her murderer known have muss.

must

'John hopes that Maria must have known her killer'

Finally, possibility epistemics are possible in the subjunctive complements of dubitatives and emotive doxastics in Romance, as we showed in section 2.2. Hence, while subjunctive mood and epistemics tend not to co-occur, epistemics are not incompatible with subjunctive mood.

\subsection{Clausal height restrictions}

Although we have argued that the distribution of epistemic modality is conditioned by the semantic class of the embedding attitude, there are clearly cases where a syntactic account is superior. As Cinque (1999) has 
demonstrated with adverbial placement, epistemic modals show systematic structural prominence effects in comparison with deontic or teleological interpretations. This pattern can be replicated with attitudinal embeddings as well. French penser ('think') allows both finite and infinitival complements, a pattern that correlates with the possibility of epistemic interpretation. Although these verbs allow epistemics when they take a finite complement, as in (70), when the complement is non-finite the modal can only be deontic, as in $(71)$, in line with the pattern of desideratives and directives in $(16,17)$. However, the restriction in (71) is in fact stricter. Recall that epistemics embedded under desideratives and directives may be rescued in 'mystery novel' scenarios. Epistemics in infinitival environments like (71), in contrast, cannot:

(70) Marie pense qu'elle doit être enceinte. Marie thinks that she must be pregnant.

'Marie thinks she deontically must be pregnant.'

'Marie thinks she epistemically must be pregnant.'

(71) Marie pense devoir être enceinte.

Marie thinks must-INF be pregnant.

'Marie thinks she deontically must be pregnant.'

'\#Marie thinks she epistemically must be pregnant.'

The contrast between (70) and (71) is explicable assuming that epistemic and deontic interpretations of modals involve distinct structural configurations, and that infinitivals are structurally too small to contain the structural position of epistemics. This argument has been made independently in the literature. Following Cinque's observations, it is argued that the syntactic position of epistemics is above Tense, in contrast to roots (cf. Iatridou 1990, Picallo 1990, Abusch 1997, Abraham 2001, Stowell 2004, Hacquard 2006, 2010). Assuming that infinitivals should be represented as TPs, the contrast follows.

The availability of a structural explanation for (71) furnishes another potential analysis of the facts in $(16,17)$ : perhaps subjunctive mood marks phrases below the position at which epistemics sit. Parallel analyses of infinitivals and subjunctive clauses are not uncommon. In fact, Picallo (1990), noting that epistemics are in general forbidden in subjunctive-marked clauses, argues that subjunctive-taking attitudes uniformly embed TPs. However, as we have argued, this explanation treats subjunctive-taking attitudes too 
uniformly. It predicts, for example, that Italian think and emotive doxastics should show epistemic dispreferences similar to those of desideratives and directives, contrary to fact. Nor does such an account explain why escape hatch scenarios for desideratives and directives may rescue an embedded epistemic (in contrast with embedded infinitivals). Of course, it is possible that certain attitudes select for larger structures, or certain attitudes in particular scenarios, but such an account must thus sacrifice a tight correlation between subjunctive-marking and smaller complement structures. In addition, a structural account does not capture the semantic generalizations underlying epistemic licensing short of stipulations about semantic selection.

\subsection{Modal concord}

Although we have spoken of the core facts in section 2 in terms of licensing, they can be naturally cast in terms of agreement: synonymy results when a necessity epistemic is in the complement of a universal doxastic or a possibility epistemic is in the complement of an existential doxastic, and neither are compatible with non-doxastic attitudes.

There exists a prior literature casting similar facts in terms of agreement. Portner (1997) discusses the emotive doxastic pray, which he notes can take an excrescent may in its complement clause:

(72) I pray that God may bless you. (Palmer 1990)

Portner argues that in such cases may is functioning as an agreement marker for subjunctive mood. Agreement with mood per se is doubtful for the Romance languages we have considered here, but the modals in question may be agreeing with modality.

A recent spate of work has discussed what the Oxford Grammar describes as modal concord, instances where a syntactic modal and synonymous modal adverb appear in the same clause (Geurts \& Huitink 2006). (Zeiljstra 2008) explicitly describes the semantics of universal epistemics under doxastic attitudes as concord, and likewise shows a similar behavior for directives and embedded deontic modals:

(73) Power carts must mandatorily be used on cart paths where provided.

Zeijlstra argues that all instances of modal concord can be analyzed as a form of syntactic agreement wherein modals are complexes of unvalued Modal Force and Flavor features that get valued by a (typically silent) modal 
operator. While this operator is usually clausemate with the expletive modal, attitude verbs constitute overt operators that Agree with and hence value modals in their domain.

This approach, coupled with the clausal height differences discussed above can correctly derive the grammaticality judgments for the core data we have considered. First, assume that doxastics alone embed clauses of sufficient size to contain epistemic modal operator heads. If there is no operator in that position, the higher attitude quantifier (which has interpretable $\forall$ Force and Epistemic Flavor features) may AGREE with an embedded modal. This will be spelled out by a necessity epistemic modal. An embedded might, while it cannot agree because of Force differences, still may be the spellout of valuation by a possibility modal operator.

In contrast, the core subjunctives, dubitatives, and emotive doxastics would all lack room for such operators. This means any epistemic in their scope must be licensed by the attitude itself. Assuming Flavor differences would rule out desideratives and directives, emotive doxastics and dubitatives would be left. If these attitudes bore valued $\exists$ Force features, embedded might would obtain, but not embedded must. Thus, as in Portner's account, might in these contexts is an uninterpreted marker of agreement.

In many ways, the account just sketched relies on central premises we have argued for already: that doxastics and emotive doxastics/dubitatives are similarly 'epistemic' in a sense desideratives and directives are not, but differ in force. However, this account makes certain incorrect predictions. First, since possibility epistemics do not inherit their modal base from the attitude, Yalcin's puzzle goes unexplained. Second, Grosz (2009) and Anand $\&$ Brasoveaunu (2009) have raised conceptual problems for the syntactic account of modal concord given above. One crucial problem these papers discuss is that negation above a modal changes its semantic force, thereby altering the modal adverbs it can co-occur with. But it is unclear how this can be cashed out syntactically, where the Force feature of the modal element itself needs to be altered. A similar problem can be constructed with emotive doxastics, which do not permit existential epistemics in the scope of negation: 
(74) John hopes that Mary \{might not, \#can't, \#must\} be the killer.

As shown in (74), if a possibility epistemic scopes over negation, it is licensed in the scope of an emotive doxastic; if it scopes underneath, it is infelicitous, like the case of a necessity epistemic. This follows given the semantics we presented above, as can't amounts to a universal assertion that violates the uncertainty inference of hope. ${ }^{25}$

\subsection{Pragmatic deviance}

We have advanced in this paper a semantic analysis of the acceptability of various epistemics, and it is worth asking how much we could accomplish by a purely pragmatic proposal. Such a proposal would, for instance, say that wanting or ordering an epistemic state is not ungrammatical per se, but simply odd - why would one want and how could one order such a thing? We believe however that there is something about the incompatibility of non-representational attitudes that goes beyond pragmatic considerations. First, it is important, as we have done here, to account for the contrast between want and hope, which behave differently with possibility epistemics but which, on first blush at least, seem rather synonymous. As we have argued, hope might $p$ still ends up comparing might $p$ statements, only with respect to subsets of the information state; want, which lacks a semantically active information state cannot do this. In short, a pragmatic account must provide an account for why emotive doxastics and dubitatives are acceptable with existential epistemics and we suspect that in doing that such accounts will end up with lexical semantics like those we have argued for, where want lacks a semantic ingredient epistemics require.

This, we think, is what underlies the significant degradation of possibility epistemics in complements of desideratives and directives. A follow-up study detailed in the Appendix shows that the French epistemic se pouvoir is significantly worst in complements of desideratives than both adverbs possible and probable. If this was all a matter of pragmatics we would

25 We predict that necessity epistemics embedded under negation should be licensed. Our own intuitions on this, exemplified in (1), seem less crisp.

(i) \%John hopes that Mary doesn't have to be the murderer.

We suspect that this is partially because the semi-modal have to underneath negation seems to disprefer epistemic interpretations generally. We leave more systematic empirical investigation to future research. 
Epistemics and attitudes

expect se pouvoir and possible to be roughly as acceptable, and more so than probable. We, however, leave it to future research to develop a full pragmatic account and contrast it to the one offered here.

\section{Conclusion}

We have shown that the distribution of epistemics in complements of attitudes is constrained by both the attitude and the force of the modal: epistemics are fully acceptable in complements of attitudes of acceptance, but unacceptable in complements of desideratives and directives. In addition, though there is a general preference for possibility epistemics over necessity ones, it is greatly exaggerated in complements of emotive doxastics and dubitatives. Interestingly, this pattern was robust across the Romance languages considered here, despite mood differences between languages.

We have argued that what determines the licensing of an epistemic is whether the embedding attitude is representational, which we have cashed out in terms of whether it provides an information state. Coupled with an anaphoric treatment of epistemics such as Yalcin's, this explained why epistemics can appear in attitudes of acceptance, but not desideratives and directives.

We have seen that while mood selection highly correlates with epistemic licensing, subjunctive and epistemics are not in perfect complementary distribution. This, we argued, follows from the fact that epistemics and subjunctive mood do not track the same phenomenon: epistemic modality tracks representationality, subjunctive mood preferences. The reason for the great overlap is that non-representational attitudes have to have a preference-based semantics - hence many preference-based attitudes are non-representational. However, the two properties are not in conflict with each other, and we thus expect to find attitudes that have both a representational and a preference component, like emotive doxastics and dubitatives. Such attitudes both license epistemics and subjunctive mood, though the semantics of these attitudes results in a ban against necessity epistemics.

In addition, although we did not offer a proposal for subjunctive mood, we have assumed that the subjunctive is an (imperfect) marker of preferences. Within attitudes in Romance, this generalization is reasonably correct, though it has famous exceptions (Italian think). However, there are other uses of the subjunctive aside from preferences - it may mark the degree of certainty of the speaker in Romanian (Farkas 1992) and, outside of attitudes entirely, has 
particular semantic effects on relative clause interpretation (Quer 1998). Our account predicts that in such cases, epistemic modality should be licensed, barring other interpretive clashes. We leave investigating this to future work. A similar point can be made about epistemic modality as well. We have investigated its distribution in attitude contexts, but it also has a limited distribution in other embedding contexts.

Finally, while we claim that attitudes be treated non-uniformly, we have presupposed that modals are a non-uniform category as well. The latter is a matter of convenience, not belief: although we have not shown it here, our account is fully compatible with systems like that of (Hacquard 2006, 2010), which provide a principled account of modal flavor in terms of height in the syntactic tree. Shouldn't we strive for uniformity across the board? ${ }^{26}$ We do not think so. While a uniform account of modals seems motivated by the fact that epistemic and root modals are often expressed by the same words cross-linguistically, no such motivation exists for attitude verbs in the languages we have looked at: they each have their own lexical entry, and there could in principle be as many kinds of attitude semantics as there are attitude verbs. While we of course would not want to endorse such a baroque system, we do believe that the various syntactic differences (mood, finiteness ...) which correlate with semantic classes of verbs (desideratives vs. doxastics ... ) suggest that all attitudes aren't cut from the same cloth.

\section{A Appendix}

This section details the procedures for the language surveys appealed to in the main text.

\section{A.1 Materials}

Items were constructed using two classes of predicates that do not take the subjunctive (semi-factives and attitudes of acceptance), one class that stably does so (desideratives/directives), and two classes that show mixed behavior across Romance (dubitatives and emotive doxastics). The verbs used for each category are listed in (75):

(75) desideratives/directives: want, wish, demand emotive doxastics: fear, hope

26 Thanks to Kai von Fintel for raising this point. 
Epistemics and attitudes

dubitatives: doubt

semi-factives: know, learn, realize

acceptance: say, think, conclude

In addition to these forms, we also included three emotive factives (happy, surprising, sad) and expectative expect. We also included two pseudodubitatives (don't think, don't doubt). The analysis which follows does not cover these classes for reasons of space. ${ }^{27}$

In order to maximize stability across Romance, we constructed items for the forms in (76) using the following three propositional complements:

(76) MODAL have known her killer

MODAL be the murderer

MODAL have had an accident

Item blocks were created by pairing each of the verbs in (75) with each of the complements in (76). Items were constructed from these by replacing MODAL in (76) with translations of must, might, and probable. (77) provides an example item set.

(77) a. Jean craint que Marie puisse avoir connu son tueur. Jean fears that Marie can-SUBJ have known her killer John fears that Mary may have known her killer

b. Jean craint que Marie doive avoir connu son tueur. Jean fears that Marie must-SUBJ have known her killer John fears that Mary must have known her killer

c. Jean craint qu'il soit probable que Marie ait connu son tueur. Jean fears that it be-SUBJ probable that Marie have known her killer John fears that it is probable that Mary knew her killer

Finally, to compare the behavior of subjunctive outside attitude environments, we also considered three constructions that typically show subjunctive mood: de dicto relative clauses, even though, and the fact that. The results of this portion of the experiment were largely inconclusive and will not be reported on here.

27 These showed a similar might/must contrast to the emotive doxastics and dubitatives (might: 5.4(1.9)/6, must: 2.6(1.8)/2). Speakers reported confusion about the pseudo-dubitative don't doubt, and the results indicated this. The pseudo-dubitative don't think showed broad similarity to doubt, but favored must in its scope (mean $=3.5$, median $=3$ ) to a non-significant degree. 
Pranav Anand and Valentine Hacquard

\begin{tabular}{lllllll}
\hline & DES/DIRECT & EMO DOX & DUBITATIVE & SEMIFACTIVE & ACCEPT. & MEAN \\
might & $3.5(2.1) / 3$ & $5.1(2) / 6$ & $6.1(1.6) / 7$ & $6.1(1.6) / 7$ & $6.4(1.2) / 7$ & $5.4(1.8) / 6$ \\
must & $1.9(1.3) / 1$ & $2.7(1.9) / 2$ & $3.1(2.1) / 2$ & $5.6(1.8) / 6$ & $6.0(1.6) / 7$ & $3.9(1.7) / 3.6$ \\
probable & $2.4(2.1) / 3$ & $4.2(2.0) / 5$ & $4.8(2.0) / 6$ & $5.6(1.8) / 7$ & $5.7(1.8) / 7$ & $5.0(1.9) / 5.4$ \\
mean & $2.8(1.7) / 2$ & $4(1.8) / 4$ & $4.6(1.8) / 4.5$ & $5.8(1.7) / 7$ & $6.2(1.6) / 7$ &
\end{tabular}

Table 4 Descriptive statistics for surveys, pooled across languages, of the form mean (standard deviation)/median.

This resulted in 63 item sets.

\section{B Methodology}

Participants saw 63 items chosen from the blocks above according to a Latin square design. Each participant thus rated 63 items, in random order. For all instances, the survey was presented online via Alex Drummond's Ibex psycholinguistic platform. Participants were asked to rate sentences between 1 (bad) and 7 (perfect). The English translation of the instructions is the following:

In this experiment, you will be required to read a number of [language] sentences. You will then be asked to rate these sentences on a scale of 1-7 (with 1 bad and 7 perfect). In rating these sentences you should consult your intuitions and consider whether you might speak these sentences or whether you think others might speak them. There are no right answers here beyond your own intuitions. You should answer each question as quickly as you can, but without rushing.

\section{Analysis}

\section{C.1 Global analysis}

Because of the limited number of Italian subjects, we elected to pool data across French, Italian, and Spanish for analysis. The overall results are given in Table 4. Ratings for responses whose times were in the $2 \%$ and $98 \%$ quantiles were removed for analysis.

For analysis of this data, we used an ordinal logistic regression model, which allow us to simultaneously account for the contributions of modal, 
Epistemics and attitudes

\begin{tabular}{lll}
\hline & MAIN EFFECT & INTERACTION EFFECT \\
positive & might & might:dubitative \\
negative & des/direct & might:des/direct \\
& dubitative & must:des/direct \\
& emotive doxastic & must:dubitative \\
& & must:emotive doxastic
\end{tabular}

Table $5 \quad$ Signs of significant effects for all results.

attitude class, language, and propositional complement to a particular rating score. Logistic regression models compute the likelihood that a given stimulus is in a particular class based upon a set of stimulus parameters provided by the experimenter. The resulting model includes a set of coefficients, one per parameter, which indicate the relative importance of each parameter. In the case of ordinal logistic regression, the classes in question are the rating scores. ${ }^{28}$ Positive coefficients correlate with higher ratings, and negative coefficients with lower ratings. For each parameter, the ratings are computed from a reference category chosen during modeling. Thus, when the model provides a positive coefficient for emotive doxastics, it means the use of an emotive doxastic correlates with increased ratings compared to the reference category for ATTITUDE TYPE (semi-factives in all models reported below). For more on ordinal logistic regression see Agresti (1996).

Ratings were fit against a model of the form MODAL x ATTITUDE TYPE + EMBEDDED PROPOSITION, yielding 16 parameters, of which 11 were significant. ${ }^{29}$ Reference points for the model were set to the semi-factives, the probability operator probable, and the had an accident complement. The details of the model are in Tables 6 and 7), but Table 5 summarizes the signs for the MODAL and ATTITUDE TYPE factors.

28 Logistic regression assumes that the logaraithm of the likelihood can be described by a linear equation of the parameter values. The ordinal model used here relies on cumulative $\log$ odds, the log of the odds that the class is some number $i$ or lower. The model equation is below, where $P(Y)$ is the probability of that class appearing, $X_{1}, \ldots, X_{n}$ are the parameters of the model, and $\beta_{1}, \ldots, \beta_{n}$ are the parameter coefficients:

(i) $\ln \left(\frac{P(Y \leq i)}{P(Y>i)}\right)=\alpha_{i}-\left(\beta_{1} X_{1} \ldots \beta_{n} X_{n}\right)$

29 A mixed effects ordinal logistic regression model was fit to the data using the ordinal package for the R programming language with SUBJECT as a random effect and a probit link function. LANGUAGE and ATTITUDE (e.g., want, wish, and demand vs. des/directives) were not significant factors ( $\chi^{2}$ model testing). 
Pranav Anand and Valentine Hacquard

\begin{tabular}{lclll}
\hline parameter & coefficient & $\begin{array}{l}\text { std error } \\
\text { modality }\end{array}$ & t-test & significance \\
a. might & 0.35 & $\begin{array}{l}\text { o.11 } \\
\text { attitude }\end{array}$ & 3.18 & .0014 \\
b. des/direct & -1.31 & 0.10 & -12.73 & $<2.22 \mathrm{e}-16$ \\
c. dubitative & -0.21 & 0.10 & -2.1 & 0.045 \\
d. emo dox & -0.56 & 0.10 & -5.42 & $3.36 \mathrm{e}-08$ \\
& & embedded proposition & & \\
e. be killer & 0.43 & 0.06 & 7.67 & $<1.73 \mathrm{e}-14$ \\
f. know killer & 0.20 & 0.05 & 3.66 & 0.00025
\end{tabular}

Table 6 Main effect coefficients

Recall that a negative coefficient indicates correlation with lower ratings and positive with higher ratings. Thus, with respect to probable, might increases ratings, and with respect to semi-factives, all the preference-directed attitudes except for dubitatives lead to decreased ratings. There is thus a penalty for any kind of intensional statement under such attitudes (assuming that probable is a reference for that).

The interaction coefficients of the model show the relative effects of the attitudes for the modals, after the main effects are taken into account. Thus, dubitatives show increased ratings for might vs. probable, on top of the general ratings preference for might. All the preference-directed attitudes show decreased ratings for must vs. probable, but only desideratives/directives show a decrease for might. This serves as the basis for the empirical claims made in section 2: desideratives/directives are allergic to both might and must, even accounting for their allergy to probable. In contrast, dubitatives, emotive factives, and emotive doxastics show a dispreference for must, but not for might. Further details of the model are summarized below, followed by discussion of the three languages.

The coefficients for the 6 main effect parameters are given in Table 6. (a) demonstrates that might was significantly more acceptable than probable in semi-factive environments and (b-d) that desideratives, dubitatives, and emotive doxastics were worse for probable than semi-factives. There was no significant differences between attitudes of acceptance and semi-factives.

The results for the 5 interaction terms are given in Table 7.3 interaction terms (b,c,e) show that must is further penalized in the environments of desideratives, emotive doxastics, and dubitatives, while might is only penal- 
Epistemics and attitudes

\begin{tabular}{lllll}
\hline parameter & coefficient & $\begin{array}{l}\text { std error } \\
\text { des/directives }\end{array}$ & t-test & significance \\
a. might:des/direct & -0.29 & 0.16 & -1.98 & .048 \\
b. must:des/direct & -0.88 & $\begin{array}{l}0.16 \\
\text { emotive doxastic }\end{array}$ & -5.59 & $2.21 \mathrm{e}-\mathrm{o} 8$ \\
& & $\begin{array}{l}\text { o.16 } \\
\text { dubitative }\end{array}$ & -7.32 & $2.39 \mathrm{e}-13$ \\
c. must:emo dox & -1.15 & 0.19 & 2.09 & .036 \\
& & 0.17 & -6.92 & $1.09 \mathrm{e}-10$
\end{tabular}

Table 7 Interaction coefficients

ized in desideratives (a), though with marginal statistical significance and substantially lower magnitude than must.

\section{C.2 Per language results}

In addition to the overall results, ratings were examined within language. For each language the results are largely those reported above, although several interaction terms do not rise to significance for the Italian data. We also report below the results of a follow-up sub-survey with 10 of our French participants for the unambiguously epistemic modal se pouvoir and the probability operator possible.

\section{C.2.1 French}

The results for the 31 French subjects are given in Table 8. In summary, the data accords with the pooled results, though the increased acceptability for French speakers of might under desiderative/directive attitudes and the decreased acceptability of might under emotive doxastics both give rise to differences with the pooled data model.

An ordinal logistic regression on this data yielded 11 significant parameters. The same 6 main-effect parameters as in Table 6 show up in Table 9, though (f), for know_killer, is marginally significant; in addition, we also observe a significant effect for dubitatives. (a) demonstrates that might was significantly more acceptable than probable in semi-factive environments and (b-d) desideratives, dubitatives, and emotive doxastics were worse for 
Pranav Anand and Valentine Hacquard

\begin{tabular}{lllllll}
\hline & DES/DIRECT & EMO DOX & DUBITATIVE & SEMIFACTIVE & ACCEPT. & MEAN \\
might & $3.7(2.1) / 3.5$ & $4.7(2.1) / 5$ & $6.4(1.2) / 7$ & $6.1(1.6) / 7$ & $6.2(1.4) / 7$ & $5.4(1.7) / 5.9$ \\
must & $1.8(1.2) / 1$ & $2.2(1.6) / 2$ & $2.7(2.0) / 2$ & $5.6(1.9) / 7$ & $6.1(1.6) / 7$ & $3.7(1.7) / 3.8$ \\
probable & $3.2(2) / 3$ & $4.6(2.1) / 5$ & $4.9(2.0) / 5$ & $5 \cdot 5(1.9) / 6$ & $5.5(2) / 7$ & $4.7(2.0) / 5.2$ \\
mean & $2.9(1.8) / 2.5$ & $3.8(1.9) / 4$ & $4.6(1.6) / 4.5$ & $5.7(1.8) / 6.7$ & $5.9(1.7) / 7$ &
\end{tabular}

Table 8 Descriptive statistics for French survey, of the form mean (standard deviation)/median.

\begin{tabular}{|c|c|c|c|c|}
\hline parameter & coefficient & $\begin{array}{l}\text { std error } \\
\text { modality }\end{array}$ & t-test & significance \\
\hline a. might & 0.60 & $\begin{array}{l}0.16 \\
\text { attitude }\end{array}$ & 3.80 & .00014 \\
\hline b. des/direct & -1.32 & 0.16 & -8.27 & $<2.22 \mathrm{e}-16$ \\
\hline c. emo dox & -0.57 & 0.16 & -3.55 & .00038 \\
\hline d. dubitative & -0.47 & $\begin{array}{l}\text { O.18 } \\
\text { embedded proposition }\end{array}$ & -2.59 & .0097 \\
\hline e. be killer & 0.49 & 0.07 & 6.64 & $3.20 \mathrm{e}-11$ \\
\hline f. know killer & 0.14 & 0.07 & 1.92 & .054 \\
\hline
\end{tabular}

Table 9 Main effect coefficients (French)

probable than semi-factives. There was no significant differences between attitudes of acceptance and semi-factives.

The results for the 5 significant interaction terms are given in Table 10. One term significant in the pooled data is non-significant for the French: might:des/direct. This lack of effect for might in core subjunctive environments is something of a surprise, though again, here this might be due to insufficient observations for the model (might:des/direct has a coefficient of -o.35 in the model, with $p<.117$ ). The French data shows one novel significant interaction for might, namely a decreased acceptability under emotive doxastics (c). This is somewhat surprising, given that we claim emotive doxastics license epistemic might freely. Examination of the emotive doxastics reveals a sharp dispreference for hope versus fear, with the biggest effect on probable and might, as shown in Table 11. This suggests that the culprit is some property of hope. Although hope is assumed to take subjunctive in French, some French speakers in fact prefer the indicative with hope; though we were unable to verify this with our participants, it is possible that the relatively low ratings were due to mood selection and not the presence of the modal. 
Epistemics and attitudes

\begin{tabular}{|c|c|c|c|c|}
\hline parameter & coefficient & $\begin{array}{l}\text { std error } \\
\text { des/directives }\end{array}$ & t-test & significance \\
\hline a. must:des/direct & -1.15 & $\begin{array}{l}0.24 \\
\text { emotive doxastic }\end{array}$ & -4.84 & $1.32 \mathrm{e}-06$ \\
\hline c. might:emo dox & -0.49 & 0.23 & -2.16 & .031 \\
\hline d. must:emo dox & -1.18 & $\begin{array}{l}\text { o.16 } \\
\text { dubitative }\end{array}$ & -7.59 & $3.13 \mathrm{e}-14$ \\
\hline d. might:dubitative & 0.69 & 0.27 & 2.53 & .011 \\
\hline e. must:dubitative & -1.37 & 0.26 & -5.21 & $1.9 \mathrm{e}-07$ \\
\hline
\end{tabular}

Table 10 Interaction coefficients (French)

\begin{tabular}{lll} 
& & \\
\hline & fear & hope \\
might & $5 \cdot 5(2.1) / 7$ & $3.7(1.9) / 3.5$ \\
must & $2.7(1.8) / 2$ & $1.9(1.4) / 1$ \\
probable & $5 \cdot 3(1.9) / 6$ & $3.6(2.0) / 3$ \\
mean & $4.5(1.9) / 5$ & $3.1(1.8) / 2.5$
\end{tabular}

Table 11 Descriptive statistics for French emotive doxastics across the modals might, must, probable.

Although there is a clear contrast between the behaviors of might and must under the core subjunctives and core indicatives, we were concerned that the acceptability judgments under the core subjunctives were inflated by the availability of root readings for pouvoir, which should be acceptable under core subjunctives. Given that the French impersonal se pouvoir, like English might disallows root readings, we conducted a follow-up survey in which participants were asked to rate sentences containing the original must as well as se pouvoir and possible. We elected to exclude semi-factives and acceptance from this follow-up to reduce length and encourage participant follow-up. 10 of our original participants completed this follow-up. The results are reported in Table 12.

We then pooled this follow-up survey data with the original French data and reanalyzed it, using emotive doxastics as a reference point (as se pouvoir was not seen with semi-factives). The resulting model resembled the original French model substantially, showing the same significant parameters. In particular, while se pouvoir showed a negative interaction with desideratives/directives, the parameter was not significant $(p>.38)$. This suggests 
Pranav Anand and Valentine Hacquard

\begin{tabular}{lllll}
\hline & des/direct & emo dox & dubitative & Mean \\
se pouvoir & $3.0(2.0) / 2$ & $5.0(1.8) / 5.5$ & $5.0(1.8) / 6$ & $4.4(2.0) / 4.6$ \\
devoir & $1.5(1) / 1$ & $2.7(1.8) / 2$ & $2.5(1.5) / 2$ & $2.4(1.5) / 2$ \\
possible & $3.9(2.1) / 4$ & $6.4(0.7) / 7$ & $6.4(1.0) / 7$ & $5.6(1.3) / 6$
\end{tabular}

Table 12 Descriptive statistics for French follow-up survey with se pouvoir in place of pouvoir, of the form mean (standard deviation)/median.

that while root readings of pouvoir was in principle possible, these did not seem to occur, in keeping with our intuitions about the relative availability of root readings for the propositional complements chosen.

\section{C.2.2 Italian}

The results for the 11 Italian participants are given in Table 13. They as well tend to mirror the overall results, though show higher overall ratings, particularly with must and the dubitatives. In addition, we lose a significant interaction for must in desiderative/directive environments, which may indicate the lack of a large enough sample.

An ordinal logistic regression on this data yielded 6 significant and 1 marginally significant parameters. Of 6 main-effect parameters in Table 6, only the effect for disideratives and directives (b) and emotive doxastics (d) are significant in the Italian model, shown in Table 14.

The results for the 4 interaction terms are given in Table 15, with (b) being marginally significant. From the original list in 7, we lose those dealing with desideratives/ directives (a,b). Thus, given that there is no main effect for modality, for Italian, might and must are equally bad under desideratives/directives. Overall, the interaction parameters in Table 15 mirror the quantificational force contrasts discussed in section 4: we retain decreased

\begin{tabular}{lllllll}
\hline & DES/DIRECT & EMO DOX & DUBITATIVE & SEMIFACTIVE & ACCEPT. & MEAN \\
might & $3(1.9) / 2$ & $5.9(1.5) / 6$ & $6.4(1.5) / 7$ & $6(1.5) / 7$ & $6.6(0.8) / 7$ & $5.6(1.4) / 5.8$ \\
must & $2.3(1.3) / 2$ & $3.4(2.2) / 3$ & $4.3(2.1) / 5$ & $6.1(1.1) / 6$ & $6.1(1.6) / 7$ & $4.4(1.7) / 4.6$ \\
probable & $3.6(2.3) / 4$ & $4.4(2.1) / 5$ & $5.4(1.6) / 6$ & $5.9(1.6) / 7$ & $6.4(1.2) / 7$ & $5.1(1.8) / 5.8$ \\
mean & $3(1.8) / 2.7$ & $4.6(1.9) / 4.7$ & $5.4(1.7) / 6$ & $6(1.4) / 6.7$ & $6.4(1.2) / 7$ &
\end{tabular}

Table 13 Descriptive statistics for Italian survey, of the form mean (standard deviation)/median. 
Epistemics and attitudes

\begin{tabular}{lllll}
\hline parameter & coefficient & $\begin{array}{l}\text { std error } \\
\text { modality } \\
\text { attitude }\end{array}$ & & significance \\
a. des/direct & -1.62 & $0.32-5.05$ & $4.21 \mathrm{e}-07$ \\
c. emo dox & -1.09 & 0.31 & -3.47 .00051 &
\end{tabular}

Table 14 Main effect coefficients (Italian)

\begin{tabular}{lllll}
\hline & & & & \\
\hline parameter & coefficient & $\begin{array}{l}\text { std error } \\
\text { emotive doxastic }\end{array}$ & t-test & significance \\
a. might:emo dox & 0.93 & 0.45 & 2.05 & .040 \\
b. must:emo dox & -0.70 & 0.44 & -1.79 & .073 \\
& & dubitative & & \\
c. might:dubitative & 1.20 & 0.55 & 2.18 & .029 \\
d. must:dubitative & -0.95 & 0.48 & -1.96 & .045 \\
Table 15 Interaction coefficients (Italian) & & \\
\hline
\end{tabular}

acceptability of must under emotive doxastics (marginally), and dubitatives. In addition, as given by (a), Italian shows an additional increased acceptability of might underneath emotive doxastics, similar to what we see for the dubitatives in (c).

\section{C.2.3 Spanish}

The results for the 21 Spanish participants are given in Table 16. Like the Italians they show higher than average ratings, but mirror the larger pattern.

The model of this data revealed 8 significant parameters, as seen in Tables 17 and 18. There were 3 main-effect parameters, 2 mirroring the embedded propositions in $(e, f)$ and one for desideratives/directives. Missing from the Spanish model were the main effects for might and for emotive doxastics; probable, emotive doxastics do not show a difference compared to semifactives; like the Italians, probable and might were not significantly different overall.

In terms of raw scores, might and probable seem to differ for emotives and acceptance. The model finds only the latter interaction significant. In the model, there are 5 significant parameters (Table 18), losing parameters for might and desideratives/directives (a) and dubitatives (e). Thus, for Spanish 
Pranav Anand and Valentine Hacquard

\begin{tabular}{lllllll}
\hline & DES/DIRECT & EMO DOX & DUBITATIVE & SEMIFACTIVE & ACCEPT. & MEAN \\
might & $3 \cdot 5(2.1) / 3$ & $5 \cdot 4(2) / 6$ & $5 \cdot 9(1.6) / 7$ & $5.9(1.8) / 7$ & $6.4(1.3) / 7$ & $5.4(1.8) / 6$ \\
must & $2.1(1.4) / 2$ & $3.1(1.9) / 3$ & $3.9(2.3) / 3$ & $5.2(1.9) / 6$ & $5 \cdot 9(1.7) / 7$ & $4(1.8) / 4.2$ \\
probable & $3 \cdot 7(2.1) / 3$ & $5 \cdot 3(1.7) / 6$ & $6(1.6) / 7$ & $5 \cdot 7(1.7) / 6.5$ & $5 \cdot 5(1.9) / 6$ & $5.2(1.9) / 5.7$ \\
mean & $3 \cdot 1(1.9) / 2.7$ & $4.2(1.9) / 4.5$ & $4.9(2) / 5$ & $5.6(1.8) / 6.5$ & $6.2(1.5) / 6.7$ &
\end{tabular}

Table 16 Descriptive statistics for Spanish survey, of the form mean (standard deviation)/median.

\begin{tabular}{lllll}
\hline & & & & \\
\hline parameter & coefficient & $\begin{array}{l}\text { std error } \\
\text { attitude }\end{array}$ & t-test & significance \\
a. des/direct & -1.23 & $\begin{array}{l}\text { o.20 } \\
\text { embedded proposition }\end{array}$ & -6.10 & $1.09 \mathrm{e}-09$ \\
b. be killer & 0.57 & 0.10 & 5.89 & $3.95 \mathrm{e}-09$ \\
c. know killer & 0.41 & 0.10 & 4.36 & $1.32 \mathrm{e}-05$
\end{tabular}

Table 17 Main effect coefficients (Spanish)

speakers, probable functions almost identically to might (leaving aside acceptance, where probable is less acceptable), and must is significantly less acceptable than both of these for all attitudes with a preference component. The fact that probable is worst than both might and must in complements of acceptance is surprising. We suspect that this may be due to stylistic factors, though further research is required.

\begin{tabular}{|c|c|c|c|c|}
\hline parameter & coefficient & $\begin{array}{l}\text { std error } \\
\text { des/direct }\end{array}$ & t-test & significance \\
\hline a. must:des/direct & -0.71 & $\begin{array}{l}0.29 \\
\text { emotive doxastic }\end{array}$ & -2.46 & 0.014 \\
\hline b. must:emo dox & -0.99 & $\begin{array}{l}0.29 \\
\text { dubitative }\end{array}$ & -3.45 & 0.00056 \\
\hline c. must:dubitative & -1.07 & $\begin{array}{l}\text { o.33 } \\
\text { acceptance }\end{array}$ & -3.27 & 0.00011 \\
\hline d. might:acceptance & 0.62 & 0.31 & 1.98 & 0.048 \\
\hline e. must: acceptance & & 0.73 & 0.30 & 2.470 .014 \\
\hline
\end{tabular}

Table 18 Interaction coefficients (Spanish) 
Epistemics and attitudes

\section{References}

Abraham, Werner. 2001. Modals: Toward explaining the epistemic nonfiniteness gap. In Reimar Mueller \& Marga Reis (eds.), Modalität und Modalverben im Deutschen, 7-36. Hamburg: Helmut Buske Verlag.

Abusch, Dorit. 1997. Sequence of tense and temporal de re. Linguistics and Philosophy 20(1). 1-50. http://dx.doi.org/10.1023/A:1005331423820.

Agresti, Alan. 1996. An introduction to categorical data analysis. John Wiley \& Sons, Inc. http://dx.doi.org/10.1002/0470114754.

Anand, Pranav \& Adrian Brasoveaunu. 2009. Modal concord as modal modification. Sinn und Bedeutung 14. 19-36.

Anand, Pranav \& Valentine Hacquard. 2009. Epistemics with attitudes. Semantics and Linguistic Theory (SALT) 18.

Bolinger, Dwight. 1968. Post-posed main phrases: An English rule for the Romance subjunctive. Canadian Journal of Linguistics 14. 3-30.

Cinque, Guglielmo. 1999. Adverbs and functional heads: A cross-linguistic perspective. New York: Oxford University Press.

Dayal, Veneeta \& Jane Grimshaw. 2009. Subordination at the interface: A quasi-subordination hypothesis. Unpublished manuscript, Rutgers.

DeRose, Keith. 1991. Epistemic possibilities. The Philosophical Review 100(4). 581-605. http://dx.doi.org/10.2307/2185175.

Drubig, Hans Bernhard. 2001. On the syntactic form of epistemic modality. Ms, University of Tübingen.

Egan, Andy, John Hawthorne \& Brian Weatherson. 2004. Epistemic modals in context. In Gerhard Preyer \& Georg Peter (eds.), Contextualism in philosophy. Oxford: Oxford University Press.

Falaus, Anamaria. 2010. Alternatives as sources of semantic dependency. Semantics and Linguistic Theory (SALT) 20.

Farkas, Donka. 1985. Intensional descriptions and the Romance subjunctive mood. New York: Garland.

Farkas, Donka. 1992. On the semantics of subjunctive complements. In Paul Hirschbühler \& E.F.K. Koerner (eds.), Romance languages and modern linguistic theory, 69-104. J. Benjamins.

Farkas, Donka. 2003. Assertion, belief and mood choice. Paper presented at ESSLI, Conditional and Unconditional Modality Workshop, Vienna.

von Fintel, Kai. 1994. Restrictions on quantifier domains. Amherst, MA: University of Massachusetts $\mathrm{PhD}$ thesis. http://semanticsarchive.net/Archive/ jA3N2IwN/. 
Pranav Anand and Valentine Hacquard

Geurts, Bart. 2005. Entertaining alternatives: Disjunctions as modals. Natural Language Semantics 13(4). 383-410. http://dx.doi.org/10.1007/s11050005-2052-4.

Geurts, Bart \& Janneke Huitink. 2006. Modal concord. In Paul Dekker \& Hedde Zeijlstra (eds.), Proceedings of ESSLLI workshop on concord phenomena at the syntax-semantics interface, 15-20.

Giannakidou, Anastasia. 1997. The landscape of polarity items. University of Groningen PhD thesis.

Giannakidou, Anastasia. 1999. Affective dependencies. Linguistics and Philosophy 22(4). 367-421. http://dx.doi.org/10.1023/A:1005492130684.

Giorgi, Alessandra \& Fabio Pianesi. 1997. Tense and aspect: From semantics to morphosyntax. Oxford: Oxford University Press.

Grosz, Patrick. 2009. Grading modality: A new approach to modal concord and its relatives. Sinn and Bedeutung 14. 185-201.

Hacquard, Valentine. 2006. Aspects of modality. Cambridge, MA: Massachusetts Institute of Technology PhD thesis. http://dx.doi.org/1721.1/37421.

Hacquard, Valentine. 2010. On the event relativity of modal auxiliaries. Natural Language Semantics 18(1). 79-114. http://dx.doi.org/10.1007/s11050o10-9056-4.

Hallden, Soren. 1957. On the logic of 'better'. Lund: Library of Theoria.

Halliday, Michael. 1970. Functional diversity in language as seen from a consideration of modality and mood in English. Foundations of Language 6. 322-361. http://www.jstor.org/stable/25000463.

Hansson, Sven Ove. 2001. The structure of values and norms. Cambridge University Press. http://dx.doi.org/10.1017/CBO9780511498466.

Heim, Irene. 1992. Presupposition projection and the semantics of attitude verbs. Journal of Semantics 9(3). 183-221. http://dx.doi.org/10.1093/jos/ 9.3.183.

Hintikka, Jaakko. 1962. Knowledge and belief. Cornell University Press.

Hooper, Joan. 1975. On assertive predicates. In John Kimball (ed.), Syntax and semantics, volume 4, 91-124. New York: Academy Press.

Hooper, Joan \& Sandra Thompson. 1973. On the applicability of root transformations. Linguistic Inquiry 4. 465-499. http://www.jstor.org/stable/ 4177789 .

Huddleston, Rodney \& Geoffrey Pullum. 2002. The Cambridge grammar of the English language. Cambridge: Cambridge University Press.

Iatridou, Sabine. 1990. About Agr(P). Linguistic Inquiry 21(4). 551-576. http: //www.jstor.org/stable/4178695. 
Epistemics and attitudes

Karttunen, Lauri. 1977. Syntax and semantics of questions. Linguistics and Philosophy 1(1). 3-44. http://dx.doi.org/10.1007/BFo035193.

Kratzer, Angelika. 1977. What must and can must and can mean. Linguistics and Philosophy 1. 337-355. http://dx.doi.org/10.1007/BFoo353453.

Kratzer, Angelika. 1981. The notional category of modality. In Hans-Jürgen Eikmeyer \& Hannes Rieser (eds.), Worlds, words, and contexts: New approaches in word semantics, 38-74. De Gruyter.

Kratzer, Angelika. 1991. Modality. In Arnim von Stechow \& Dieter Wunderlich (eds.), Semantics: An international handbook of contemporary research, 639-650. Berlin \& New York: Mouton de Gruyter.

Kratzer, Angelika. 2006. Decomposing attitude verbs. Talk given at The Hebrew University of Jerusalem. http://semanticsarchive.net/Archive/ DcwY2JkM/attitude-verbs20o6.pdf.

Kratzer, Angelika. 20o9. Modals and context-dependency. Colloquium, Harvard University, February 20, 2009.

Lassiter, Daniel. 2010. Gradable epistemic modals, probability and scale structure. Semantics and Linguistic Theory (SALT) 20. 197-215.

MacFarlane, John. 2011. Epistemic modals are assessment-sensitive. In Andy Egan \& Brian Weatherson (eds.), Epistemic modality. Oxford: Oxford University Press. http://dx.doi.org/10.1093/acprof:oso/9780199591596.0o3. ooo6.

Moltmann, Friederike. 2003. Propositional attitudes without propositions. Synthese (135). http://dx.doi.org/10.1023/A:1022945009188.

Moulton, Keir. 2008. Clausal complementation and the wager-class. North East Linguistic Society (NELS) 38.

Palmer, Frank Robert. 1990. Modality and the English modals. 2nd. Longman.

Palmer, Frank Robert. 2001. Mood and modality. 2nd. Cambridge: Cambridge University Press.

Pesetsky, David. 1992. Zero syntax II: Infinitival complementation. http: //web.mit.edu/linguistics/www/pesetsky/infins.pdf.

Picallo, M. Carme. 1990. Modal verbs in Catalan. Natural Language and Linguistic Theory 8(2). 285-312. http://dx.doi.org/10.1007/BFo0208525.

Portner, Paul. 1992. Situation theory and the semantics of propositional expressions. Amherst, MA: University of Massachusetts $\mathrm{PhD}$ thesis. http: //scholarworks.umass.edu/dissertations/AAI9305882.

Portner, Paul. 1997. The semantics of mood, complementation, and conversational force. Natural Language Semantics 5(2). 167-212. http://dx.doi.org/ 10.1023/A:1008280630142. 
Pranav Anand and Valentine Hacquard

Quer, Josep. 1998. Mood at the interface. Utrecht Institute of Linguistics, OTS PhD thesis.

Rooryck, Johan. 2001. Evidentiality, parts I and II. Glot International 5(4-5).

Rooth, Mats E. 1985. Association with focus. Amherst, MA: University of Massachusetts PhD thesis. http://scholarworks.umass.edu/dissertations/ AAI8509599.

Rubinstein, Aynat. 2012. Roots of modality. Amherst, MA: University of Massachusetts $\mathrm{PhD}$ thesis. http://scholarworks.umass.edu/dissertations/ AAI3545982.

Sauerland, Uli. 2004. The interpretation of traces. Natural Language Semantics 12. 63-127. http://dx.doi.org/10.1023/B:NALS.ooooo11201.91994.4f.

Scheffler, Tatjana. 2008. Semantic operators in different dimensions. Philadelphia, PA: University of Pennsylvania PhD thesis.

Schlenker, Philippe. 2005. The lazy frenchman's approach to the subjunctive: Speculations on reference to worlds and semantic defaults in the analysis of mood. In Twan Geerts, Ivo van Ginneken \& Haike Jacobs (eds.), Romance languages and linguistic theory 2003 (Current Issues in Linguistic Theory 270), 269-310. Amsterdam \& Philadelphia, PA: John Benjamins.

Searle, John R. \& Daniel Vanderveken. 1985. Foundations of illocutionary logic. Cambridge: Cambridge University Press.

Simons, Mandy. 2007. Observations on embedding verbs, evidentiality and presupposition. Lingua 117(6). 1037-1056. http://dx.doi.org/10.1016/j. lingua.2006.05.006.

Stalnaker, Robert. 1984. Inquiry. Cambridge, MA: MIT Press.

Stephenson, Tamina. 2007. Towards a theory of subjective meaning. Cambridge, MA: Massachusetts Institute of Technology PhD thesis. http://dx. doi.org/1721.1/41695.

Stowell, Tim. 1981. Origins of phrase structure. Cambridge, MA: Massachusetts Institute of Technology PhD thesis. http://dx.doi.org/1721.1/15626.

Stowell, Tim. 2004. Tense and modals. In Jacqueline Guéron \& Jacqueline LeCarme (eds.), The syntax of time. Cambridge, MA: MIT Press.

Swanson, Eric. 2006. Something might might mean. University of Michigan ms.

Truckenbrodt, Hubert. 2006. On the semantic motivation of syntactic verb movement to C in German. Theoretical Linguistics 32. 257-306. http: //dx.doi.org/10.1515/TL.2006.018.

Urmson, J.O. 1952. Parenthetical verbs. Mind 61(244). 480-496. http://dx.doi. org/10.1093/mind/LXI.244.480. 
Epistemics and attitudes

Veltman, Frank. 1996. Defaults in update semantics. Journal of Philosophical Logic 25(3). 221-261. http://dx.doi.org/10.1007/BFoo248150.

Villalta, Elisabeth. 2000. Spanish subjunctive clauses require ordered alternatives. Semantics and Linguistic Theory (SALT) 10. 239-256.

Villalta, Elisabeth. 2008. Mood and gradability: An investigation of the subjunctive mood in Spanish. Linguistics and Philosophy 31(4). 467-522. http: //dx.doi.org/10.1007/s10988-008-9046-x.

von Wright, G. H. 1963. The logic of preference. Edinburgh: Edinburgh University Press.

Yalcin, Seth. 2007. Epistemic modals. Mind 116. 983-1026. http://dx.doi.org/ $10.1093 / \mathrm{mind} /$ fzmg83.

Yalcin, Seth. 2010. Probability operators. Philosophy Compass 5(11). 916-936. http://dx.doi.org/10.1111/j.1747-9991.2010.00360.x.

Zeiljstra, Hedde. 2008. Modal concord is syntactic agreement. Semantics and Linguistic Theory (SALT) 17. 317-332.

Pranav Anand

Stevenson Academic Services

1156 High St.

Santa Cruz, CA 95065

panand@ucsc.edu
Valentine Hacquard

1401 Marie Mount Hall

College Park, MD 20742

hacquard@umd.edu 